\title{
Full Vehicle Vibration and Noise Analysis Based on Substructure Power Flow
}

\author{
Zhien Liu, ${ }^{1,2}$ Shuai Yuan, ${ }^{1,2}$ Shenghao Xiao, ${ }^{1,2}$ Songze Du, ${ }^{1,2}$ Yan Zhang, ${ }^{3}$ and Chihua Lu ${ }^{1,2}$ \\ ${ }^{1}$ Hubei Key Laboratory of Advanced Technology for Automotive Components, Wuhan University of Technology, Wuhan 430070, China \\ ${ }^{2}$ Hubei Collaborative Innovation Center for Automotive Components Technology, Wuhan 430070, China \\ ${ }^{3}$ Automotive Engineering Institute, Guangzhou Automobile Group Co., Ltd., Guangzhou 511434, China \\ Correspondence should be addressed to Shuai Yuan; 420789340@qq.com
}

Received 30 November 2016; Revised 6 March 2017; Accepted 20 March 2017; Published 30 April 2017

Academic Editor: Mario Terzo

Copyright (C) 2017 Zhien Liu et al. This is an open access article distributed under the Creative Commons Attribution License, which permits unrestricted use, distribution, and reproduction in any medium, provided the original work is properly cited.

Combining substructure and power flow theory, in this paper an external program is written to control MSC. Nastran solution process and the substructure frequency response are also formulated accordingly. Based on a simple vehicle model, characteristics of vibration, noise, and power flow are studied, respectively. After being compared with the result of conventional FEM (finite element method), the new method is confirmed to be feasible. When it comes to a vehicle with the problem of low-frequency noise, finite element models of substructures for vehicle body and chassis are established, respectively. In addition, substructure power flow method is also employed to examine the transfer characteristics of multidimensional vibration energy for the whole vehicle system. By virtue of the adjustment stiffness of drive shaft support and bushes at rear suspension lower arm, the vehicle interior noise is decreased by about $3 \mathrm{~dB}$ when the engine speed is near $1050 \mathrm{rpm}$ and $1650 \mathrm{rpm}$ in experiment. At the same time, this method can increase the computation efficiency by $78 \%, 38 \%$, and $98 \%$ when it comes to the optimization of chassis structure, body structure, and vibration isolation components, respectively.

\section{Introduction}

With the continuous enhancement of life quality of human beings, consumers' requirements of vehicle NVH (noise, vibration, and harshness) performance become accordingly more stringent. The NVH performance is a key factor which determines if a vehicle can stand on the market. The NVH performance is mainly measured based on two indicators, body vibration and interior noise. Powertrain and vehicle driving road are considered as the main excitation sources. Through chassis components and isolation components, the energy is transferred in multiple directions and eventually input to the body structure, leading to vibration of thin plate parts. Besides, coupled with interior acoustic cavity, vibrations will generate low-frequency noise peaks, which may influence the comfort of passengers. As a result, reducing the vibration energy input to vehicle body and controlling vibration of thin plate parts are two effective ways to make the enhancement of vehicle NVH performance [1].

Power flow takes into account vibration speed, vibration transfer force, and their phase relations at the same time and reflects the characteristics of structure vibration response from nature. Combined with the power flow theory and FEM, the substructure method is developed in this work $[2,3]$. Through using a simple vehicle model, the characteristics of vibration, noise, and power flow are, respectively, investigated. After being compared with the theoretical solution and solving results of conventional FEM, the feasibility and accuracy of the new method are verified. Besides, a kind of vehicle model with low-frequency noise problem is also studied in this paper, and the transfer characteristics of vehicle system multidimensional vibration energy are obtained by virtue of substructure power flow analysis method. Finally, an improved proposal is made, which is verified to be useful through experiments.

\section{Substructure Power Flow}

2.1. Theory of Power Flow. The power flow describes the energy transfer at each structure point, and it can guide the 


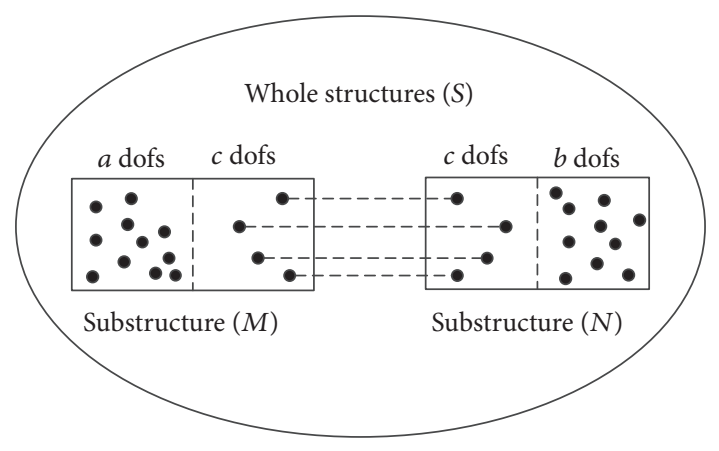

FIGURE 1: Schematic of substructure.

control of structure and noise efficiently. The power flow is defined as follows $[4,5]$ :

$$
P=F(t) \cdot v(t) .
$$

In this formula, $P$ is the power flow of vibration transfer, $F(t)$ is the external force loaded at a structure point, and $v(t)$ is the velocity response of a point under the load $F(t)$.

It is difficult to characterize the structure vibration with transient power flow, so the average power flow is taken as the evaluation index to describe the energy characteristic of structure response. Vibration power flow is expressed as follows:

$$
P=\frac{1}{T} \lim _{T \rightarrow 0} \int_{0}^{T} F(t) \cdot v(t) d t .
$$

The time averaged vibration power is given by [6]

$$
P=\frac{1}{2} \operatorname{Re}\left\{F \cdot v^{*}\right\}
$$

or

$$
P=\frac{1}{2}|F||V| \cos \phi,
$$

where $*$ denotes the complex conjugate and $\phi$ is the relative phase.

2.2. The Frequency Response Function of Substructures. As the schematic showed in Figure 1, the whole structure $S$ consists of substructures $M$ and $N$. Substructure $M$ is a system with $(a+c)$ DOFs, and substructure $N$ is a system with $(b+c)$ DOFs. The interface between $M$ and $N$ has $c$ DOFs $[7,8]$.

Steady-state frequency response equation is

$$
\left(-\omega^{2}[M]+i \omega[B]+[K]\right)\{X\}=[Z]\{X\}=\{F\} .
$$

In this equation, $\omega$ is excitation frequency; $[M]$ is the mass matrix of the system; $[B]$ is the damping matrix of system; $[K]$ is the stiffness matrix of system; $\{X\}$ is the displacement response of system structure; $[Z]$ is the dynamic stiffness matrix of system; $\{F\}$ is the external excitation of system [9].

The above equation for displacement response is solved as follows:

$$
\{X\}=[Z]^{-1}\{F\}=[H]\{F\},
$$

where $[H]$ is the mobility matrix, also known as FRF (frequency response function) matrix.

The equation of motion for each subsystem in the frequency domain for the complex displacement $\left\{X_{n}\right\}$ is

$$
\{X\}_{n}=[H]_{n n}\{F\}_{n},
$$

where $[H]_{n n}$ is the complex admittance matrix (displacement/force) and $\{F\}_{n}$ is the applied force vector.

The subscript $n$ represents the total number of DOFs for each subsystem.

$$
\begin{array}{ll}
n=a+c & \text { for subsystem } M, \\
n=b+c & \text { for subsystem } N .
\end{array}
$$

Note that the number $c$ is the same for both subsystems. Subsystem $M$ can be partitioned as

$$
\left\{\begin{array}{l}
\left\{X^{M}\right\}_{a} \\
\left\{X^{M}\right\}_{c}
\end{array}\right\}_{n}=\left[\begin{array}{ll}
{\left[H^{M}\right]_{a a}} & {\left[H^{M}\right]_{a c}} \\
{\left[H^{M}\right]_{c a}} & {\left[H^{M}\right]_{c c}}
\end{array}\right]_{n n}\left\{\begin{array}{l}
\left\{F^{M}\right\}_{a} \\
\left\{F^{M}\right\}_{c}
\end{array}\right\}_{n} .
$$

Subsystem $N$ can be partitioned as

$$
\left\{\begin{array}{l}
\left\{X^{N}\right\}_{b} \\
\left\{X^{N}\right\}_{c}
\end{array}\right\}_{n}=\left[\begin{array}{ll}
{\left[H^{N}\right]_{b b}} & {\left[H^{N}\right]_{b c}} \\
{\left[H^{N}\right]_{c b}} & {\left[H^{N}\right]_{c c}}
\end{array}\right]_{n n}\left\{\begin{array}{l}
\left\{F^{N}\right\}_{b} \\
\left\{F^{N}\right\}_{c}
\end{array}\right\}_{n} .
$$

Let the superscript $S$ represent the combined system where subsystems $M$ and $N$ are rigidly connected at $c$ DOFs. It requires

$$
\begin{aligned}
& \left\{X^{M}\right\}_{c}=\left\{X^{N}\right\}_{c}=\left\{X^{S}\right\}_{c}, \\
& \left\{F^{M}\right\}_{c}=\left\{F^{N}\right\}_{c}=\left\{F^{S}\right\}_{c} .
\end{aligned}
$$

The FRFs of the system can be represented as

$$
\begin{aligned}
& \left\{\begin{array}{l}
\left\{X^{S}\right\}_{a} \\
\left\{X^{S}\right\}_{c} \\
\left\{X^{S}\right\}_{b}
\end{array}\right\}_{n} \\
& =\left[\begin{array}{lll}
{\left[H^{S}\right]_{a a}} & {\left[H^{S}\right]_{a c}} & {\left[H^{S}\right]_{a b}} \\
{\left[H^{S}\right]_{c a}} & {\left[H^{S}\right]_{c c}} & {\left[H^{S}\right]_{c b}} \\
{\left[H^{S}\right]_{b a}} & {\left[H^{S}\right]_{b c}} & {\left[H^{S}\right]_{b b}}
\end{array}\right]_{n n}\left\{\begin{array}{l}
\left\{F^{S}\right\}_{a} \\
\left\{F^{S}\right\}_{c} \\
\left\{F^{S}\right\}_{b}
\end{array}\right\}_{n} .
\end{aligned}
$$

The connection DOFs from the partitioned equation (10) for subsystems $M$ and $N$ are

$$
\begin{aligned}
& \left\{X^{N}\right\}_{c}=\left[H^{N}\right]_{c b}\left\{F^{N}\right\}_{b}+\left[H^{N}\right]_{c c}\left\{F^{N}\right\}_{c} \\
& \left\{X^{M}\right\}_{c}=\left[H^{M}\right]_{c a}\left\{F^{M}\right\}_{a}+\left[H^{M}\right]_{c c}\left\{F^{M}\right\}_{c} .
\end{aligned}
$$

Now let $\left\{\widehat{F}^{M}\right\}_{\mathcal{c}}$ and $\left\{\widehat{F}^{N}\right\}_{c}$ be the internal transmitted forces at interfaces for subsystems $M$ and $N$, respectively. 
Note that for the fully coupled system

$$
\begin{aligned}
\left\{F^{S}\right\}_{c} & =\left\{\widehat{F}^{M}\right\}_{c}+\left\{\widehat{F}^{N}\right\}_{c}, \\
\left\{\widehat{F}^{M}\right\}_{c} & =\left\{F^{S}\right\}_{c}-\left\{\widehat{F}^{N}\right\}_{c}, \\
\left\{\widehat{F}^{N}\right\}_{c} & =\left\{F^{S}\right\}_{c}-\left\{\widehat{F}^{M}\right\}_{c} .
\end{aligned}
$$

Substitute these transmitted forces into (14) in preparation for coupling

$$
\begin{aligned}
& \left\{X^{M}\right\}_{c}=\left[H^{M}\right]_{c a}\left\{F^{M}\right\}_{a}+\left[H^{M}\right]_{c c}\left\{\widehat{F}^{M}\right\}_{c} \\
& \left\{X^{N}\right\}_{c}=\left[H^{N}\right]_{c b}\left\{F^{N}\right\}_{b}+\left[H^{N}\right]_{c c}\left\{\widehat{F}^{N}\right\}_{c} .
\end{aligned}
$$

Set (18) equal to each other according to (11),

$$
\begin{aligned}
{\left[H^{M}\right]_{c c}\left\{\widehat{F}^{M}\right\}_{c}=} & {\left[H^{N}\right]_{c b}\left\{F^{N}\right\}_{b}+\left[H^{N}\right]_{c c}\left\{\widehat{F}^{N}\right\}_{c} } \\
& -\left[H^{M}\right]_{c a}\left\{F^{M}\right\}_{a} .
\end{aligned}
$$

Substituting (17) into (19), the internal transmitted forces can be obtained

$$
\begin{aligned}
& \left\{\widehat{F}^{M}\right\}_{c}=\left[\left[H^{M}\right]_{c c}+\left[H^{N}\right]_{c c}\right]^{-1}\left\{\left[H^{N}\right]_{c b}\left\{F^{N}\right\}_{b}\right. \\
& \left.+\left[H^{N}\right]_{c c}\left\{F^{S}\right\}_{c}-\left[H^{M}\right]_{c a}\left\{F^{M}\right\}_{a}\right\}, \\
& \left\{\widehat{F}^{N}\right\}_{c}=\left[\left[H^{M}\right]_{c c}+\left[H^{N}\right]_{c c}\right]^{-1}\left\{\left[H^{M}\right]_{c a}\left\{F^{M}\right\}_{a}\right. \\
& \left.\quad+\left[H^{M}\right]_{c c}\left\{F^{S}\right\}_{c}-\left[H^{N}\right]_{c b}\left\{F^{N}\right\}_{b}\right\} .
\end{aligned}
$$

Now let us obtain coupled FRF equation $\left[H^{S}\right]_{a a}$ as an example.

Recall from equation the coupled system (13),

$$
\begin{aligned}
\left\{X^{S}\right\}_{a}= & {\left[H^{S}\right]_{a a}\left\{F^{S}\right\}_{a}+\left[H^{S}\right]_{a c}\left\{F^{S}\right\}_{c} } \\
& +\left[H^{S}\right]_{a b}\left\{F^{S}\right\}_{b} .
\end{aligned}
$$

Recall from (9) the uncoupled subsystem $M$.

$$
\left\{X^{M}\right\}_{a}=\left[H^{M}\right]_{a a}\left\{F^{M}\right\}_{a}+\left[H^{M}\right]_{a c}\left\{F^{M}\right\}_{c} .
$$

For the coupled system, (23) becomes

$$
\left\{X^{S}\right\}_{a}=\left[H^{M}\right]_{a a}\left\{F^{S}\right\}_{a}+\left[H^{M}\right]_{a c}\left\{\widehat{F}^{M}\right\}_{c} .
$$

Substitute (22) into (24).

$$
\begin{aligned}
{\left[H^{S}\right]_{a a}\left\{F^{S}\right\}_{a}=} & {\left[H^{M}\right]_{a a}\left\{F^{S}\right\}_{a}+\left[H^{M}\right]_{a c}\left\{\widehat{F}^{M}\right\}_{c} } \\
& -\left[H^{S}\right]_{a c}\left\{F^{S}\right\}_{c}-\left[H^{S}\right]_{a b}\left\{F^{S}\right\}_{b} .
\end{aligned}
$$

Substitute (20) into (25).

$$
\begin{aligned}
& {\left[H^{S}\right]_{a a}\left\{F^{S}\right\}_{a}=-\left[H^{S}\right]_{a c}\left\{F^{S}\right\}_{c}-\left[H^{S}\right]_{a b}\left\{F^{S}\right\}_{b}} \\
& +\left[H^{M}\right]_{a a}\left\{F^{S}\right\}_{a}+\left[H^{M}\right]_{a c}\left\{\left\{\left[H^{M}\right]_{c c}+\left[H^{N}\right]_{c c}\right\}^{-1}\right. \\
& \cdot\left\{\left[H^{N}\right]_{c b}\left\{F^{N}\right\}_{b}-\left[H^{M}\right]_{c a}\left\{F^{M}\right\}_{a}\right. \\
& \left.\left.\quad+\left[H^{N}\right]_{c c}\left\{F^{S}\right\}_{c}\right\}\right\}, \\
& \left\{F^{S}\right\}_{b}=0 \\
& \left\{F^{S}\right\}_{c}=0 \\
& \left\{F^{N}\right\}_{b}=0 \\
& {\left[H^{S}\right]_{a a}\left\{F^{S}\right\}_{a}=\left[H^{M}\right]_{a a}\left\{F^{S}\right\}_{a}-\left[H^{M}\right]_{a c}\left\{\left[H^{M}\right]_{c c}\right.} \\
& \left.\quad+\left[H^{N}\right]_{c c}\right\}^{-1}\left\{\left[H^{M}\right]_{c a}\left\{F^{M}\right\}_{a}\right\} .
\end{aligned}
$$
$\left\{F^{S}\right\}_{a}$.

Note that at the system level $\left\{F^{M}\right\}_{a}$ can be replaced by Thus,

$$
\begin{aligned}
{\left[H^{S}\right]_{a a}\left\{F^{S}\right\}_{a}=[} & \left.H^{M}\right]_{a a}\left\{F^{S}\right\}_{a}-\left[H^{M}\right]_{a c} \\
& \cdot\left\{\left[H^{M}\right]_{c c}+\left[H^{N}\right]_{c c}\right\}^{-1} \\
& \cdot\left\{\left[H^{M}\right]_{c a}\left\{F^{S}\right\}_{a}\right\} .
\end{aligned}
$$

Divide each side of (29) by $\left\{F^{\mathcal{S}}\right\}_{a}$

$$
\begin{aligned}
{\left[H^{S}\right]_{a a}=} & {\left[H^{M}\right]_{a a} } \\
& -\left[H^{M}\right]_{a c}\left[\left[H^{M}\right]_{c c}+\left[H^{N}\right]_{c c}\right]^{-1}\left[H^{M}\right]_{c a} .
\end{aligned}
$$

An individual admittance function $\left[h^{S}\right]_{i j}$ can be accessed via

$$
\begin{aligned}
{\left[h^{S}\right]_{i j}=} & {\left[h^{M}\right]_{i j} } \\
& -\left[H^{M}\right]_{i c}\left\{\left[H^{M}\right]_{c c}+\left[H^{N}\right]_{c c}\right\}^{-1}\left[H^{M}\right]_{c j} .
\end{aligned}
$$

By now, the entire FRF matrix of the coupled structure $S$ can be calculated according to the FRF matrix of substructures $M$ and $N$. And the displacement response of each DOF can be obtained according to (6), and its derivative is velocity response.

2.3. Acoustic-Structure Coupling. The acoustic analysis is based on inviscid flow with linear pressure-density relation as

$$
\frac{1}{\rho} \nabla P+\ddot{u}=0 .
$$

And the continuity equation is

$$
P+\beta(\nabla \cdot u)=0,
$$


where $P$ and $u$ are the pressure of the fluid domain and displacement of the structural domain, respectively, and $\beta$ and $\rho$ are the compressibility of the fluid domain and density of the structural domain, respectively.

Combining the above equations, the governing equation of the fluid domain is

$$
\frac{\ddot{P}}{\beta}-\frac{1}{\rho} \nabla^{2} P=0 .
$$

After finite element discretization, the assembly of equations for the fluid domain is

$$
M_{P} \ddot{P}+B_{P} \dot{P}+K_{P} P-A \ddot{u}=S_{P},
$$

where $M_{P}, B_{P}, K_{P}$, and $S_{P}$ are the mass matrix, damping matrix, stiffness matrix, and source vector, respectively, of the fluid domain.

The matrix $A$ represents the interface matrix and $\ddot{u}$ is the acceleration of the structural grids at the fluid-structure interface (the pressure gradient at the interface will be influenced by the acceleration of structure nodes).

The structural equation assembly can be written as

$$
M_{S} \ddot{u}+B_{S} \ddot{u}+K_{S} u+A^{T} P=S_{S},
$$

where $M_{S}, B_{S}, K_{S}$, and $S_{S}$ are mass matrix, damping matrix, stiffness matrix, and source vector, respectively, of the structural domain.

The matrix $A$ represents the transpose of interface matrix and $\ddot{u}$ is the pressure at the interface fluid nodes at fluidstructure interface (the displacement, velocity, and acceleration of structure nodes at the interface will be influenced by the pressure at interface fluid nodes).

Therefore, the combined fluid-structure interface equation is

$$
\begin{aligned}
& {\left[\begin{array}{cc}
M_{S} & 0 \\
-A & M_{P}
\end{array}\right]\left[\begin{array}{l}
\ddot{u} \\
\ddot{P}
\end{array}\right]+\left[\begin{array}{cc}
B_{S} & 0 \\
0 & B_{P}
\end{array}\right]\left[\begin{array}{l}
\dot{u} \\
\dot{P}
\end{array}\right]+\left[\begin{array}{cc}
K_{S} & A^{T} \\
0 & K_{P}
\end{array}\right]\left[\begin{array}{l}
u \\
P
\end{array}\right]} \\
& =\left[\begin{array}{l}
S_{S} \\
S_{P}
\end{array}\right] .
\end{aligned}
$$

The above equations are solved simultaneously for unknowns in structure and fluid domains, either by direct frequency response or by modal frequency response [10].

\section{Simple Vehicle Model}

3.1. Conventional Method of Frequency Response Analysis. A 3D vehicle model is built and is simplified to three parts: body, acoustic cavity, and chassis. The body structure is simulated as shell elements CQUAD4, whose thickness is $2 \mathrm{~mm}$ with a total of about 12 thousand of elements. The acoustic cavity model can be built with the closed body model and solid element CHEXA with acoustic properties, and there are about 66 thousand of elements in acoustic cavity model. According to (37), the interface between acoustic cavity and structure panel is coupled with interpolation of vibration velocity. The

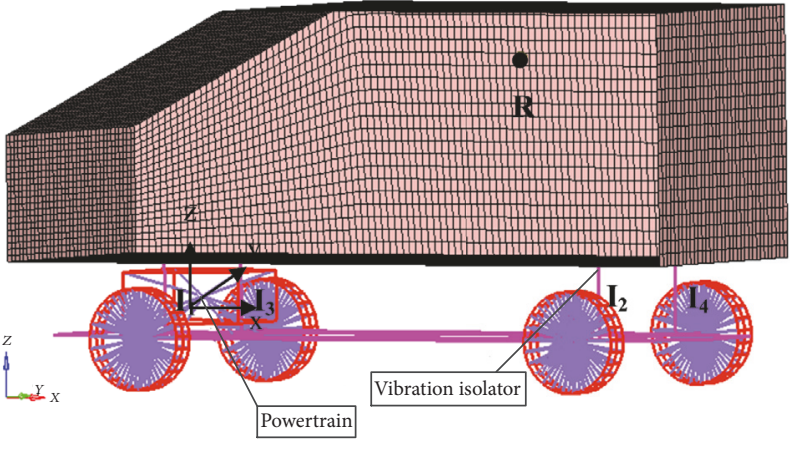

FIGURE 2: Simple vehicle model for conventional method.

chassis model is built with a total of 500 CBEAM elements of $40 \mathrm{~mm}$ inside diameter and $60 \mathrm{~mm}$ outside diameter. Taking the vibration isolation and damping of tires and mounting structures into consideration, lumped mass element CONM2 and one-dimensional dummy element PLOTEL were employed to build the power train model. The body and chassis are connected through 4 simplified elastic isolators which are simulated with CBUSH elements. The simple finite element model of the vehicle is established with reference to the vehicle coordinate system, as shown in Figure 2.

Unit sinusoidal excitation torque was input at the mass center of powertrain in rotation direction of crankshaft at a frequency ranging from $20 \mathrm{~Hz}$ to $200 \mathrm{~Hz}$ with increment of $1 \mathrm{~Hz}$. The vibration and noise characteristics using conventional and substructure methods are, respectively, examined. The isolator can reduce the vibration transmission energy. Its master side is connected to chassis and slave side is connected to body structure. The excitation power is transferred to the body though 4 isolators, and the radiated noise from the vehicle is generated by body structure vibrations.

3.2. Substructure Method of Frequency Response Analysis. From Figure 3, the vehicle model is simplified to 2 substructures. Substructures 1 and 2 are connected through the multidimensional springs with stiffness and damping parameters. Substructure 1 is composed of body structure and acoustic cavity, while substructure 2 is composed of powertrain and chassis. The entire FRF matrix of the coupled structure is obtained in accordance with (30). The vibration and noise are analyzed with the application of substructure method on this model.

3.2.1. Vibration Characteristics. Taking the velocity characteristic of the master side and slave side of $I_{1}$ as an example, a comparison between the frequency response result of conventional method and substructure method was drawn. As shown in Figures 4 and 5, the curves of two methods coincide with each other very well, verifying the accuracy of the substructure method applied to the complex structure modeling and vibration response analysis.

3.2.2. Noise Characteristics. With the acoustic characteristic at an interior point $R$ as an example, a comparison between 


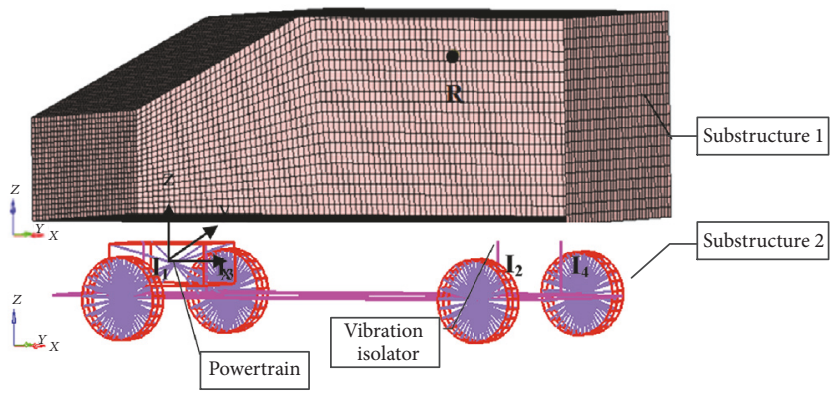

Figure 3: Simple vehicle model for substructure method.

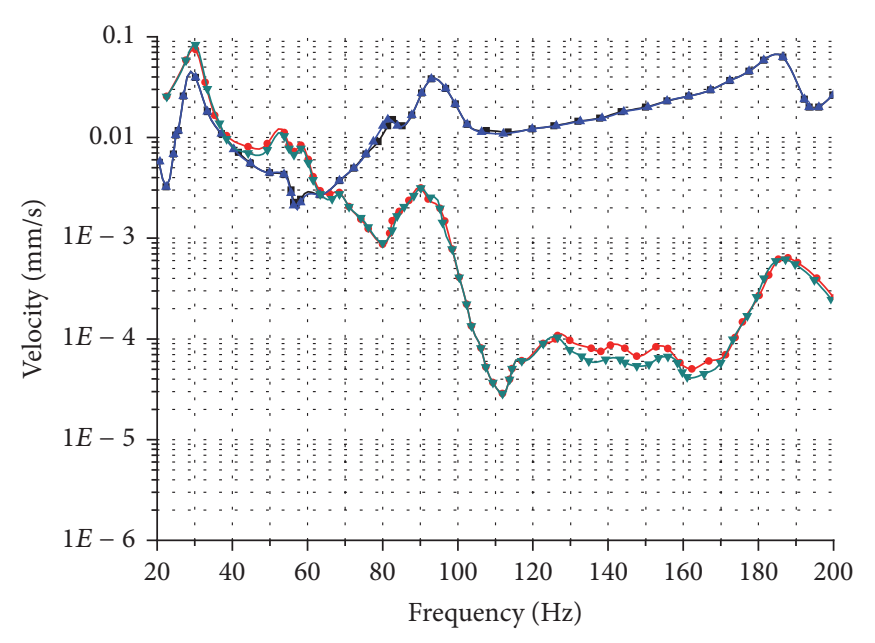

$\rightarrow I_{1}$-master- $X$-conventional

- $I_{1}$-slave- $X$-conventional

$\longrightarrow I_{1}$-master- $X$-substructure

$\rightarrow I_{1}$-slave- $X$-substructure

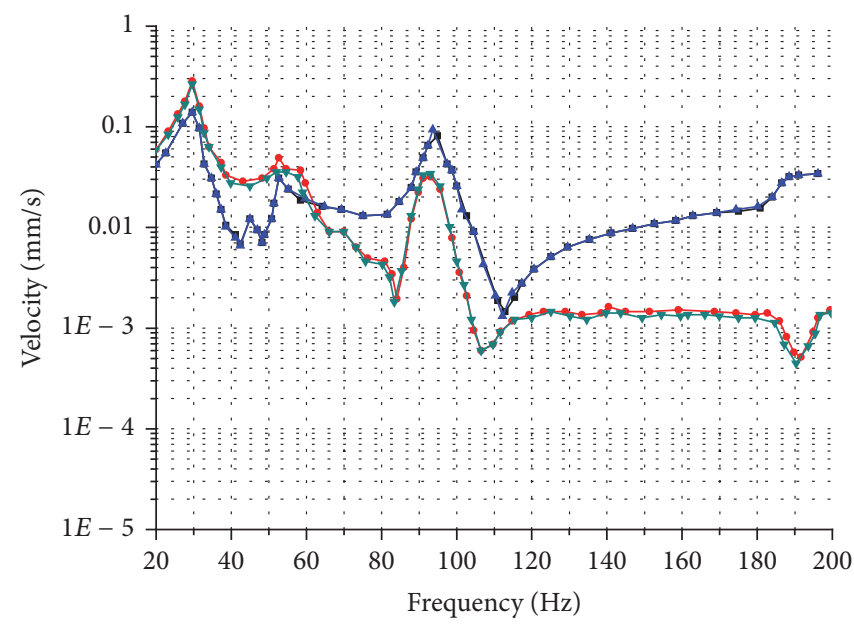

$\rightarrow I_{1}$-master- $Y$-conventional

$\rightarrow I_{1}$-slave- $Y$-conventional

$\neg I_{1}$-master- $Y$-substructure

$\rightarrow I_{1}$-slave- $Y$-substructure

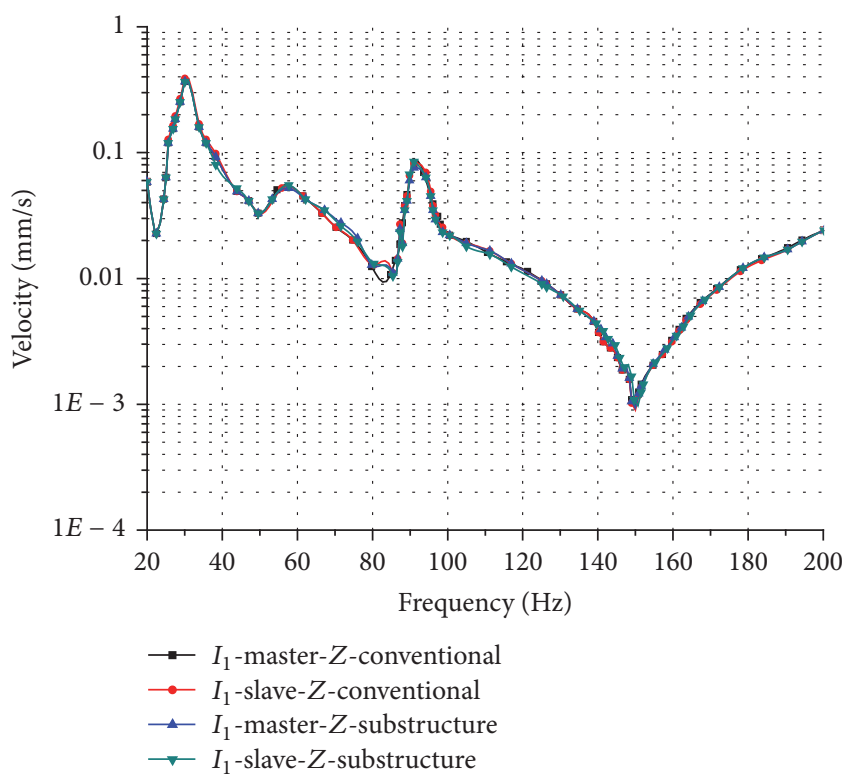

FIGURE 4: Velocity characteristic of $I_{1}$. 


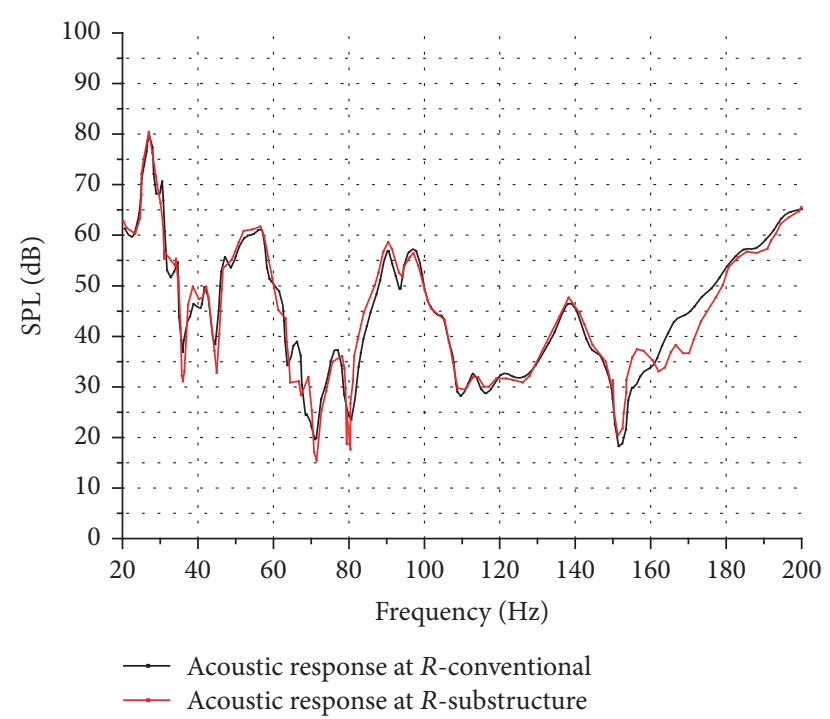

FIgURE 5: Acoustic characteristic at point $R$.

the analysis results of two methods was drawn. The acoustic response curve based on the substructure method largely retains the features of the curve based on the conventional method. There are only a few deviations when the frequency is higher than $150 \mathrm{~Hz}$, confirming the consistency of the results and further verifying the accuracy of substructure method applied to the complex structure modeling and noise analysis. Besides, the substructure method can be used in the $\mathrm{NVH}$ field in automotive engineering.

\section{Full Vehicle Finite Element Model for NVH Analysis}

Directed at the low and middle frequency noise problem existing in FR cars, the full vehicle finite element model was established for $\mathrm{NVH}$ analysis [11]. The vibration energy characteristics were analyzed through using substructure power flow, and an improvement scheme was proposed to verify the scheme by experiment test. The full vehicle model includes trimmed body, acoustic cavity, and chassis assembly. In order to facilitate model building and management, the steering system (up) and steering system (down), respectively, represent two parts above and below the cardan joint at the middle of the steering system. The trimmed body contains body in white, closures, trim, accessories, and steering system (up) and the acoustic cavity includes air cavity and seat cavity. Besides, the chassis assembly is composed of steering system (down), powertrain system, front suspension system, transmission system, rear suspension system, and exhaust system.

In terms of $\mathrm{NVH}$ analysis, body structure is a significant transmission path. To a great extent, the response of body structure determines the interior noise level [12]. As a result, it is necessary to ensure the accuracy of the finite element model of the car body. Body in white consists of lots of thin plate parts and welding spots. The welding spot can be simulated with ACM as shown in Figure 6 [13].
Based on the 3D geometry model of body in white, small structures which nearly have no effects on body response were simplified, including pipe bundle, wire harness, and bolts. In accordance with the experience, the uniform structural and fluid damping coefficient of this type of vehicle are chosen as 0.04 and 0.12 , respectively. All thin plates are modeled with shell elements. The average size is $10 \mathrm{~mm} \times$ $10 \mathrm{~mm}$, and there is a total of about 600,000 shell elements. To ensure the credibility of the analysis results, element quality was inspected according to Table 1 , until all the elements met the criterion.

As shown in Figure 7(a), according to the basic steps and guidelines above, the finite element model for body in white was set up. The free modal of body in white was calculated, and the result was compared with the test data. Through repeatedly examining and debugging the finite element model, the deviation of simulation result and test data should be controlled within $10 \%$, and then the final model of body in white can be confirmed to be usable for vehicle model [14]. Figure 7(b) is modal test of the body in white. From Table 2, a comparison between the finite element analysis result and test result was made.

In Table 2, it can be observed that the free modal analysis result of finite element conforms very well to the test result, and the vibration modes are consistent with each other. The natural frequencies of the 1st, 3rd, and 4 th order have very small deviations, which are under $1 \%$. The deviation of the 2nd order is relatively big reaching $7.15 \%$ but still lies in acceptable range of $10 \%$. The global twist of body in white is in the 4 th mode, whose benchmark deviation of modal frequency is quite small, reaching only $0.98 \%$. Moreover, the global twist mode significantly influences the interior noise in the NVH analysis [15]. Therefore, the finite element model of body in white is finalized, which can exactly reflect the vibration characteristic of the true vehicle. At the same time, it is verified that the simplification of welding spot is acceptable. Figure 8 is the free modal shape of the body in white. The global modal shape is twist, and others are local modes. The main vibration happens at back door and roof.

According to the criterion of element quality in the table, the full vehicle finite element model for NVH analysis is established as shown in Figure 9.

4.1. Conventional Frequency Response Analysis Method. Based on the finite element model in Figure 9, the coordinates of powertrain mass center are set up. Excitation at the mass center of powertrain is applied in rotation direction of crankshaft, and the elastic contact points between tire and ground are constrained. By virtue of conventional frequency response analysis method of MSC.NASTRAN, the vehicle vibration and the interior acoustic response from $20 \mathrm{~Hz}$ to $100 \mathrm{~Hz}$ are analyzed. The curves of vibration and noise response are considered as important evaluation of vehicle NVH performance. The range of modal solution is $0-200 \mathrm{~Hz}$ and the excitation range is $0-400 \mathrm{~Hz}$.

4.2. Substructure Frequency Response Analysis Method. Substructure 1 consists of trimmed body and acoustic cavity, and substructure 2 is composed of chassis assembly. The two 


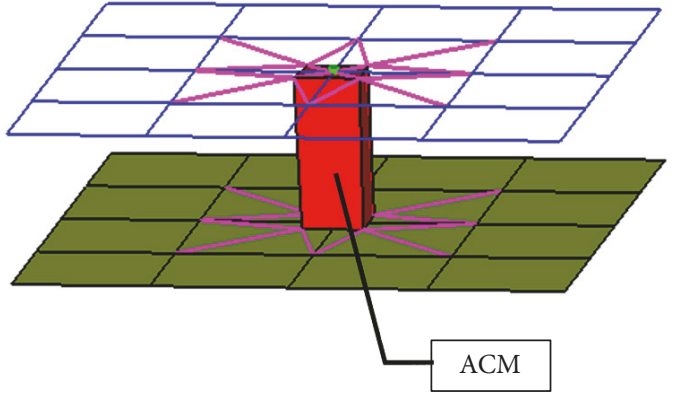

(a) 2-layer welding

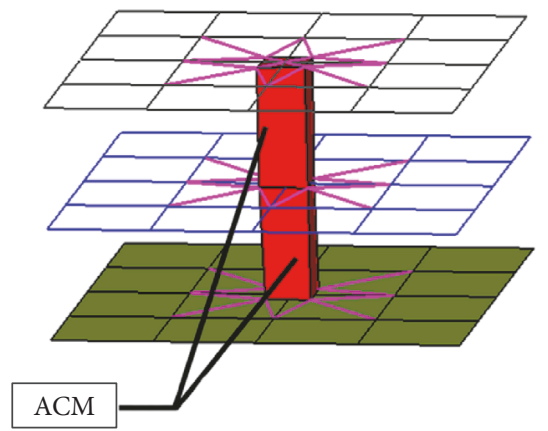

(b) 3-layer welding

FIGURE 6: Schematic of ACM welding spot

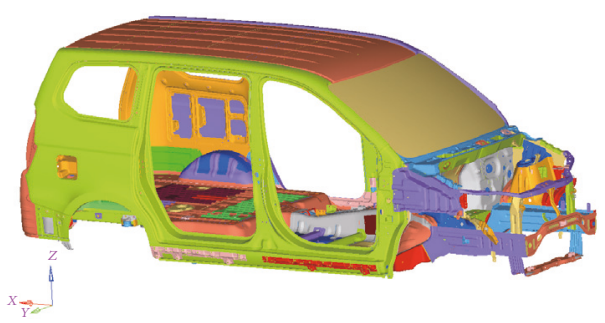

(a) Finite element model

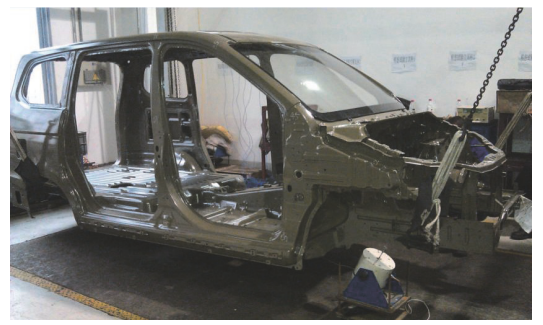

(b) Modal test

FIGURE 7: Body in white.

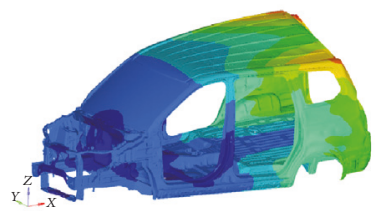

(a) 1 st order $28.82 \mathrm{~Hz}$

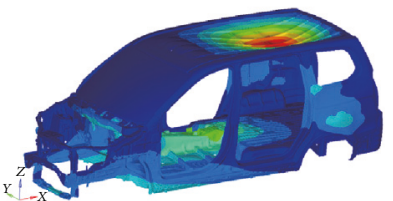

(b) 2nd order $35.35 \mathrm{~Hz}$

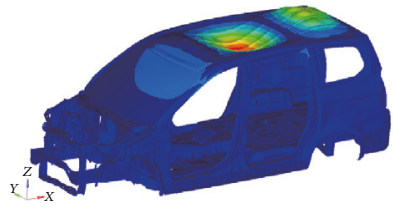

(c) 3 rd order $38.9 \mathrm{~Hz}$

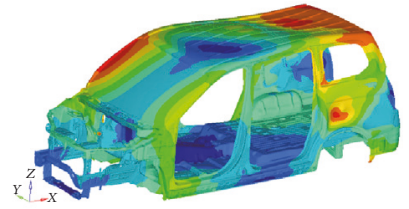

(d) 4 th order $42.54 \mathrm{~Hz}$

Figure 8: Modal shape.

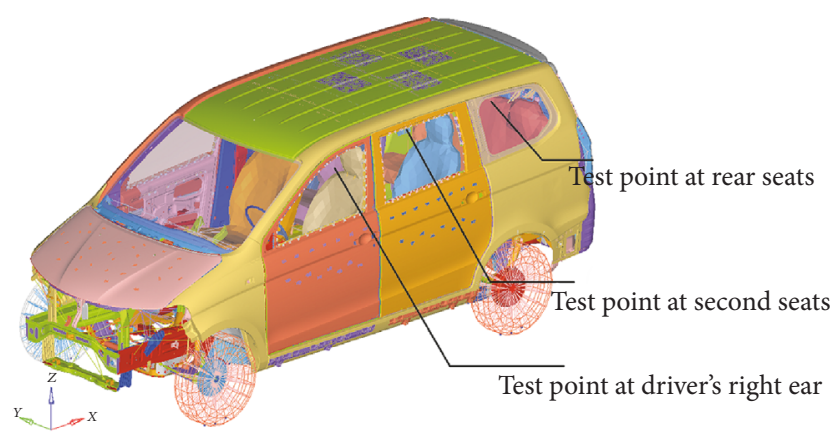

FIGURE 9: Finite element model of full vehicle.

substructures are connected through the vibration isolators at the points, as is shown in Figure 10. The loads and constraints, which are identical to those in conventional method, are applied to the model, and the vibration and noise results will be obtained due to the substructure frequency response analysis method $[7,8]$.

4.2.1. Vibration Characteristics. Based on the above NVH finite element model, the substructure power flow analysis method was used to obtain the velocity response at the connection point between the transmission shaft support bushing and the body. Besides, comparisons with the vibration response result of conventional FEM are presented in Figure 11 .

The curves in Figure 11 indicate that the conventional FEM result and the substructure FEM result agree with each other very well. Both of them demonstrate that an obvious peak exists around $32 \mathrm{~Hz}$ in $y$ translation and $z$ translation, proving the accuracy of this finite element model.

4.2.2. Noise Characteristics. Based on the NVH finite element model, the substructure power flow analysis method is employed to obtain the interior acoustic response, which is compared with the result obtained through conventional method. Besides, the curves are plotted in Figure 12. Conclusions can be drawn as follows:

(1) Two sets of curves are of high consistency. In $20-100 \mathrm{~Hz}$ full frequency range, the acoustic characteristic curve to a great extent retains peak frequency features of conventional FEM frequency response result. There is little difference between noise peak 
TABLE 1: Criterion of element check.

\begin{tabular}{cccccccc}
\hline & Aspect & Length & Skew $/^{\circ}$ & Warpage $^{\circ}$ & Trias angle $^{\circ}$ & Quads angle $^{\circ}$ & Jacobian $^{\circ}$ \\
\hline Threshold & $\leqslant 5$ & $\geqslant 1$ & $\leqslant 40$ & $\leqslant 15$ & {$[30,100]$} & {$[45,130]$} & $\geqslant 0.6$ \\
\hline
\end{tabular}

TABLE 2: Benchmark of body in white modal.

\begin{tabular}{|c|c|c|c|c|}
\hline Modal order & Test results & FEM results & Relative error & Vibration mode \\
\hline 1 & 28.78 & 28.82 & $+0.01 \%$ & Deformation of back door \\
\hline 2 & 32.99 & 35.35 & $+7.15 \%$ & First order of roof \\
\hline 3 & 38.99 & 38.91 & $-0.21 \%$ & Second order of roof \\
\hline 4 & 42.96 & 42.54 & $-0.98 \%$ & Global twist \\
\hline
\end{tabular}

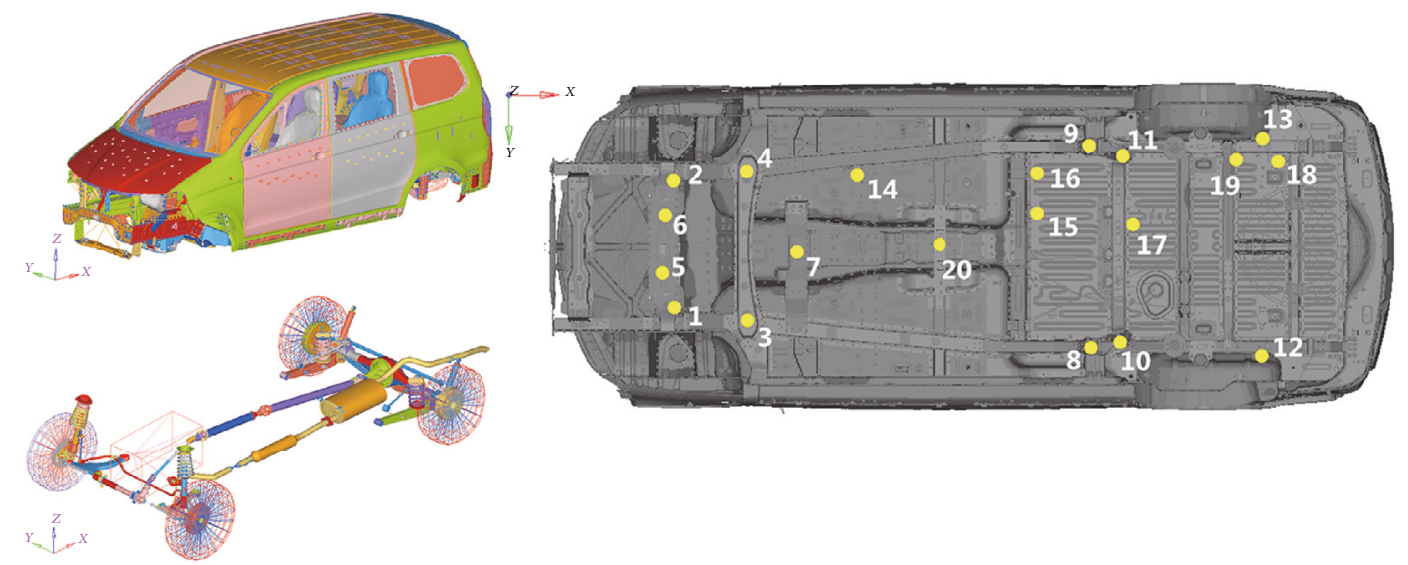

FIGURE 10: Substructures and connection point.

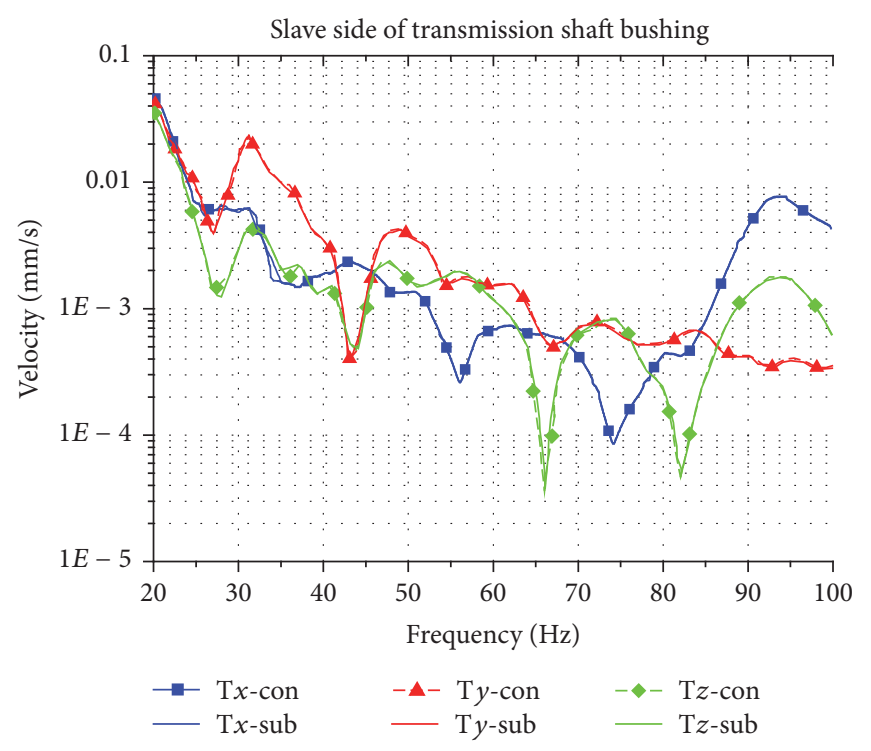

(a) Translation

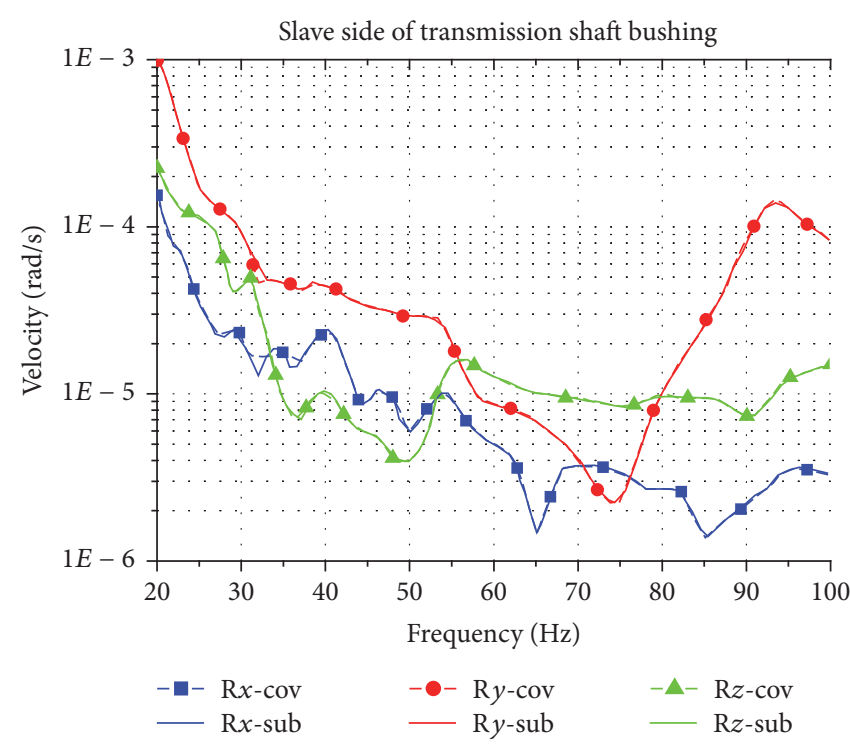

(b) Rotation

FIGURE 11: Velocity response. 


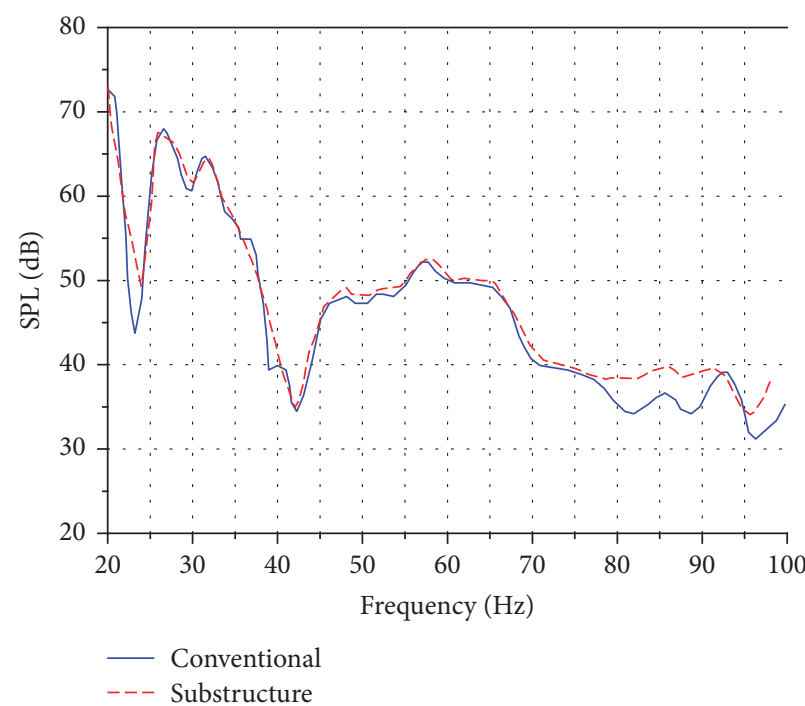

(a) Driver's right ear

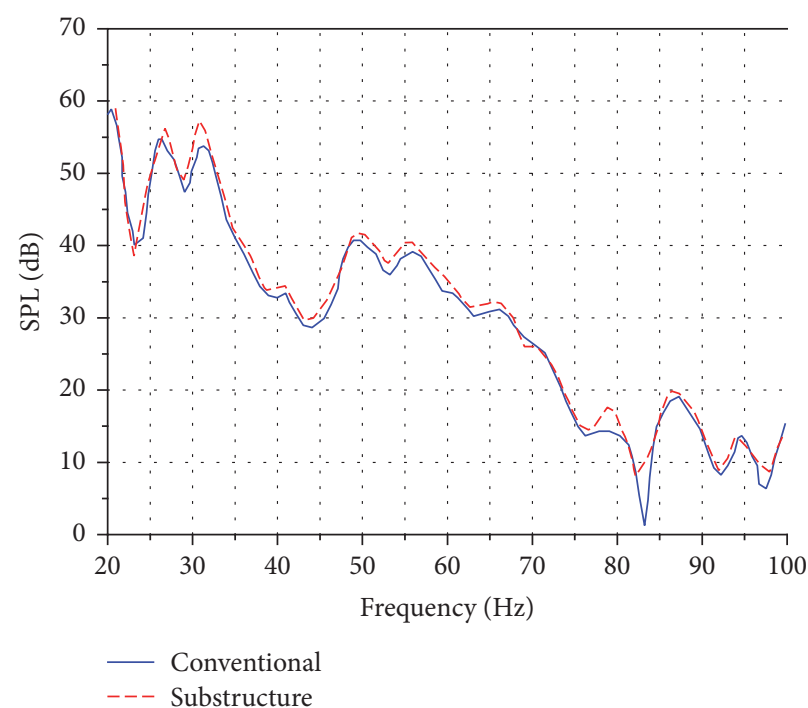

(b) Middle of second seats

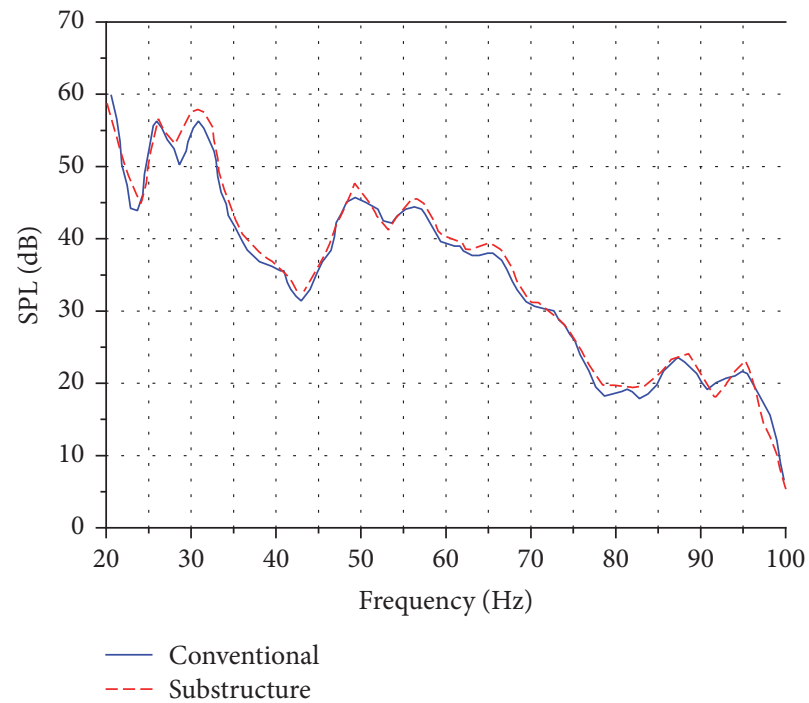

(c) Middle of rear seats

Figure 12: Characteristics of interior noise response.

values of two results, which proves that the result of substructure power flow method is sufficiently accurate.

(2) $32 \mathrm{~Hz}, 48 \mathrm{~Hz}$, and $56 \mathrm{~Hz}$ are potential frequencies corresponding to noise peak. The interior noise response curves peak at around $32 \mathrm{~Hz}, 48 \mathrm{~Hz}$, and $56 \mathrm{~Hz}$, and it becomes most distinct at $32 \mathrm{~Hz}$. At the location of driver's right ear, the noise reaches $68 \mathrm{~dB}$; besides, at the middle of the second and back row seats, the noise reaches $71 \mathrm{~dB}$.

4.3. Substructure Power Flow Analysis. The substructure FEM of frequency response is employed to analyze the structure vibration velocity and vibration transmission force. Combined with the basic theory of power flow, the characteristics of vibration transmission energy between substructures are investigated. Due to the scalar property of power flow, the risky transmission path can be ranked and identified, which can also be applied in conducting the adjustment of vibration isolation system and body structure. The vibration excitation is generated by powertrain. Through the powertrain mounts, front suspension bushing, rear suspension bushing, exhaust pipe hook, transmission shaft support bushing, and chassis structure, the excitation is transferred to the body structure. When it comes to the vehicle vibration system, the inputted multidimensional energy to response substructure, which is the body structure, should be highlighted.

With reference to NVH analysis power flow FEM model, the FRF matrix of chassis substructure and body structure are calculated, respectively, with MSC.NASTRAN. Subsequently, the frequency response analysis is carried out. Later, vibration velocities and vibration transmission forces at 20 elastic connecting points between body substructure and chassis substructure are obtained, and the total power of every 


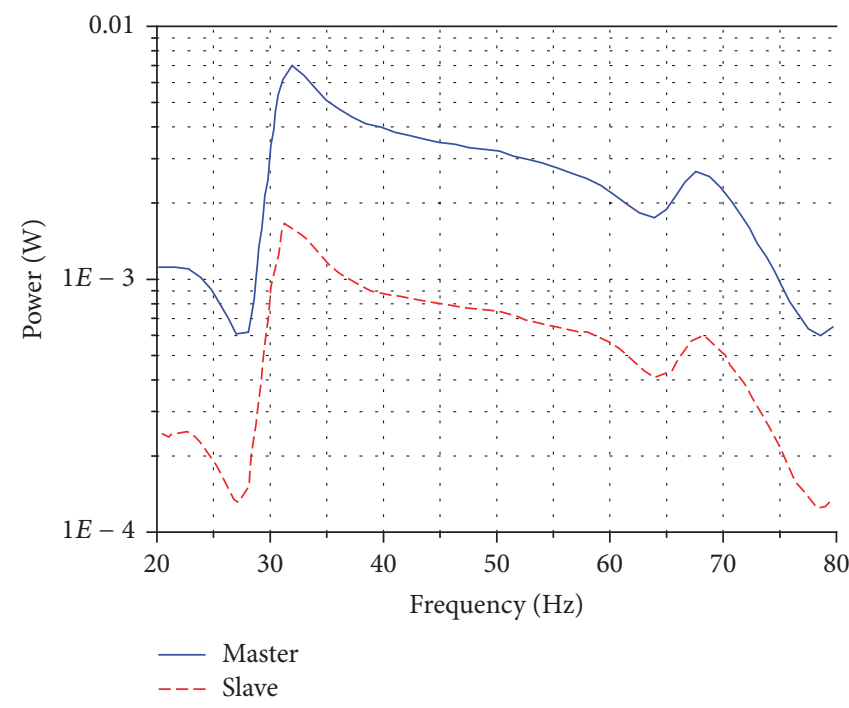

(a) Transmission shaft support bushing

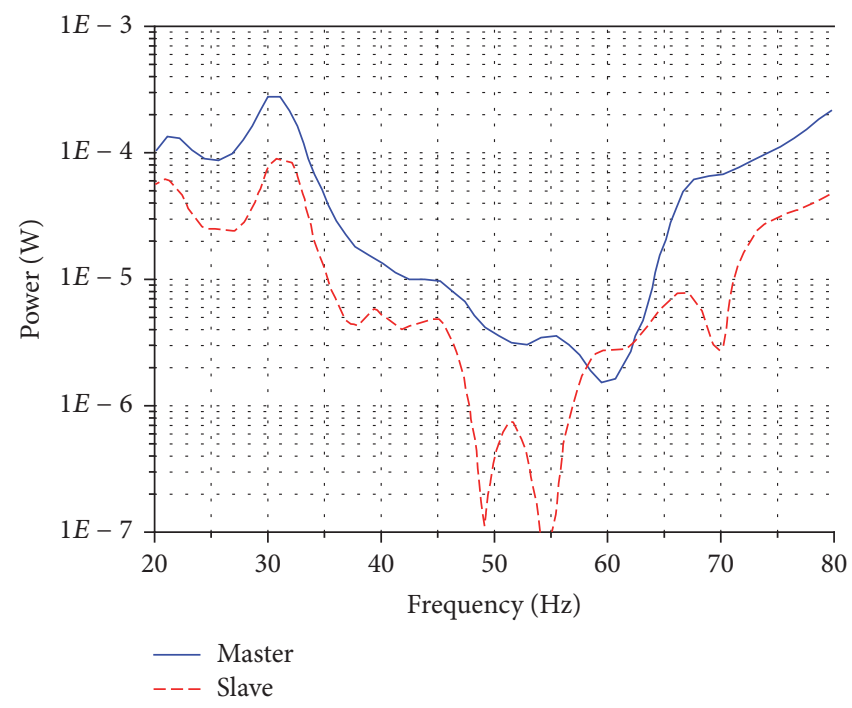

(b) Rear suspension lower arm (right)

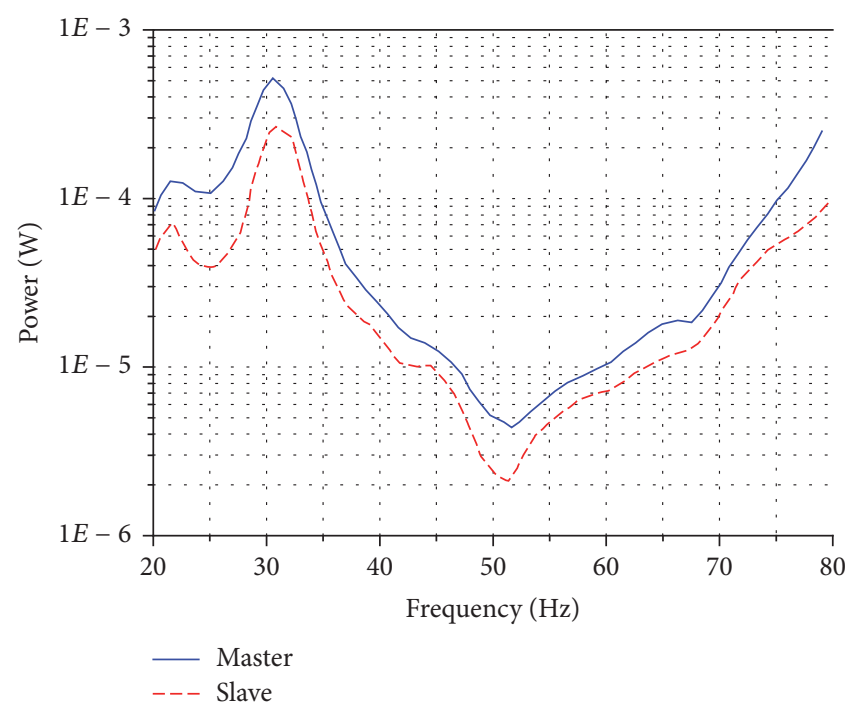

(c) Rear suspension lower arm (left)

FIGURE 13: Total power.

connecting point in the body structure can be figured out according to (4). Moreover, the power flow at the 20 locations shown in Figure 10 is quantified, and the first 3 locations in which most energy is input to the body structure are found, which are connecting points at transmission shaft support bushing, rear suspension lower arm bushing (right), and rear suspension lower arm bushing (left), all considered as the risky transmission path of interior noise. The powerfrequency curve is shown in Figure 13. In the master side, the energy is input to the interface; in the slave side, the energy is output from the interface, which is tantamount to the energy transferred to the body. Drawing a comparison between the power on the master side and the slave side on the transmission paths, it can be found that the power on the slave side is less than that on the master side, implying that the rubber bushings attenuate the vibration energy. The curve distinctly peaks at around $32 \mathrm{~Hz}$, which is consistent with the risky interior noise frequency. Therefore, there is a certain association between the noise response and risky transmission paths.

Furthermore, the power flow in different direction of motion is investigated, by which the composition of total power flow can be determined. Subsequently, the isolator parameters in key direction can be adjusted, and the power flow contribution of this direction can be reduced. Figure 14 shows the power flow curve of transmission shaft support bushing in 6 directions. Through the comparison of total power curves, it can be easily found that the rotation about $Z$ direction is the key movement direction as well as an important component of total power. Besides, there are distinct peaks at around $32 \mathrm{~Hz}$ in this direction, and the peak value is very close to the total power value.

Figure 15 presents the power curve of rear suspension lower arm bushing in 6 directions. In the comparison among 


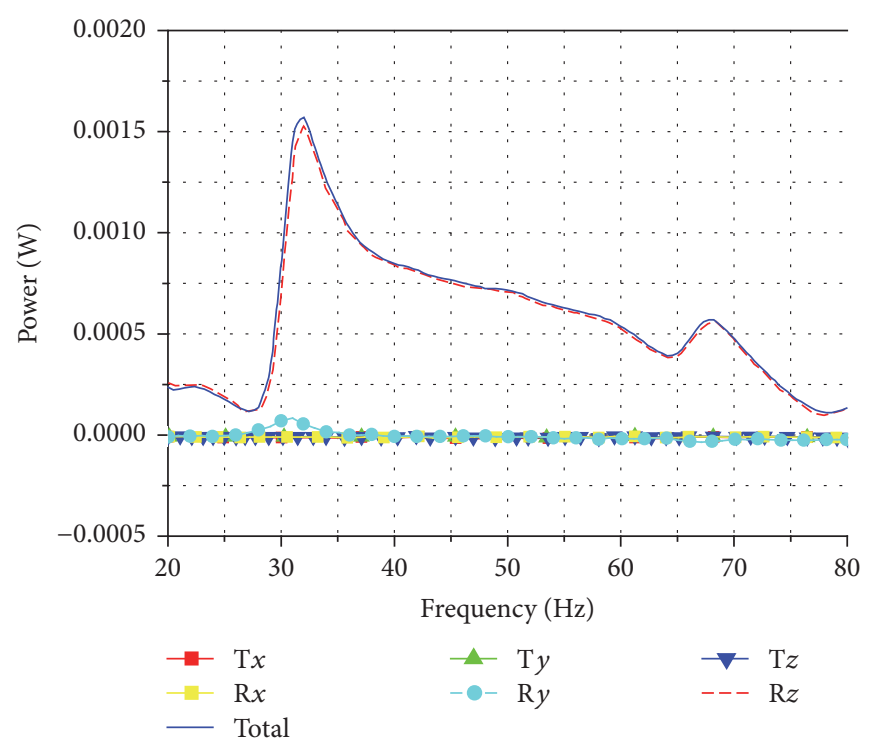

FIGURE 14: Power of transmission shaft support bushing in 6 directions.

the curve of each direction with the total power curve, it can be observed that the translation along $x$ axis is the key direction of motion as well as the most important composition of the total power. In addition, there are distinct peaks at around $32 \mathrm{~Hz}$ in this direction, and the peak value is very close to the total power value.

The total powers in 20 transmission paths are calculated, respectively, and ranked, and 3 risky transmission paths are identified, respectively, transmission shaft support bushing, rear suspension lower arm bushing (right), and rear suspension lower arm bushing (left). Furthermore, the power flow characteristics in each direction are analyzed, by which the main motion directions of transmission shaft support bushing and rear suspension lower arm bushing are identified, which are the rotation along $Z$ direction and the translation along $X$ direction, respectively. According to the findings, the feature parameter of isolator can be optimized.

\section{Efficiency}

There is a total of about 2 million nodes in the NVH finite element model of the full vehicle, and about 9.5 million DOFs need to be solved.

In order to overcome the practical limitations of long computation time, extensive work has been performed, and AMLS (automated multilevel substructuring) and FastFRS (fast frequency response solver) methods are currently commonly used to solve large FE modes.

In AMLS (automated multilevel substructuring), a finite element model of a structure is automatically divided into two substructures, each of which is then subdivided into its own substructures. This subdivision is repeated recursively until thousands of substructures have been defined in a tree topology [16]. FastFRS performs only one numerical operation whose cost is proportional to the cube of the number of modes, rather than one such operation at each response frequency.
With the aim to compare substructure method with the conventional method, the AMLS and fastFRS method are not used in this paper. However, it is worth mentioning that the efficiency will be improved if AMLS and fastFRS were adopted. Besides, comparing with using AMLS and fastFRS methods only, if the substructure method was adopted, the required computer storage and computational time will significantly reduce when a single substructure was changed.

The model is submitted to a Dell workstation, equipped with double $3.46 \mathrm{GHz}$ Intel Xeon X5690 CPUs and $48 \mathrm{~GB}$ memory. The computing time is about 5 hours for the vibration and noise response with conventional FE method.

The chassis substructure model contains about 680 thousand nodes, and about 3.5 million DOFs need to be solved. FRF solution takes about 1 hour. Meanwhile, the body substructure model contains about 1.32 million nodes, and about 6 million DOFs need to be solved. Its FRF solution also takes about 1 hour. It only takes nearly 4 minutes to invoke the substructure FRF matrix and carry out the full vehicle substructure frequency response analysis, which is equivalent to 0.07 hours. The analyzing time of the conventional method and the substructure method is displayed in Table 3.

As for substructure finite element analysis of frequency response, the chassis substructure FRF is firstly calculated and then the body substructure FRF. Besides, the total time needed to solve the full vehicle FRF is about 4.07 hours. Comparing with the conventional FEM analysis of frequency response, 56 minutes are saved, indicating that the efficiency is improved by $18 \%$.

Obviously, the application of the substructure finite element analysis of frequency response in the NVH model greatly improves the efficiency, especially for models with a great number of DOFs, whose changed structure schemes require repeated calculations. The application of this method will substantially shorten the calculation time.

(1) The chassis substructure requires to be optimized. Because the analysis model retains the substructure 


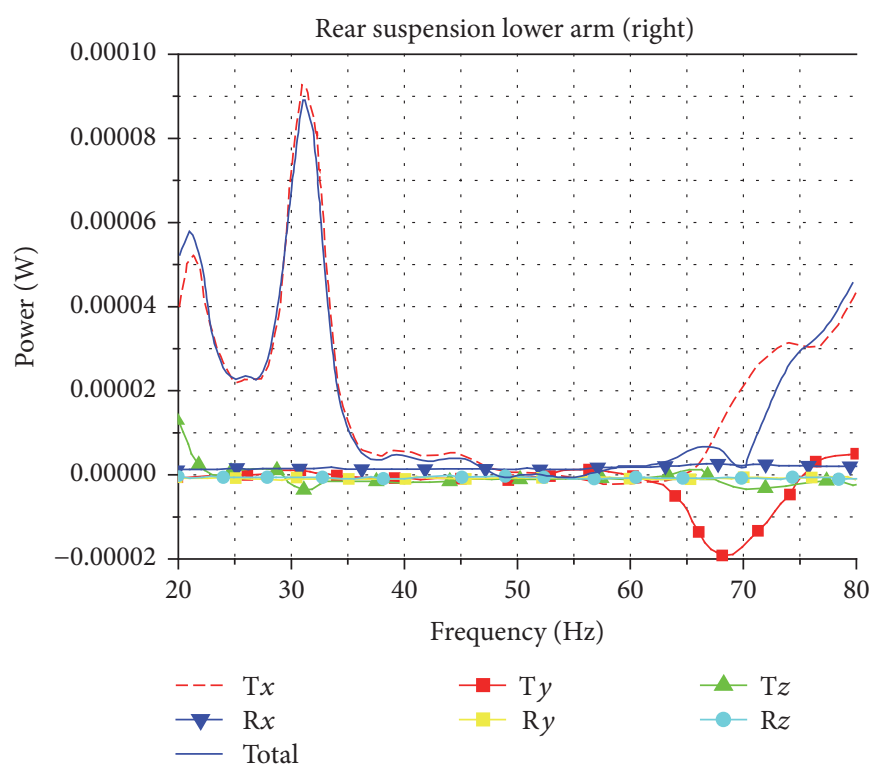

(a) Right

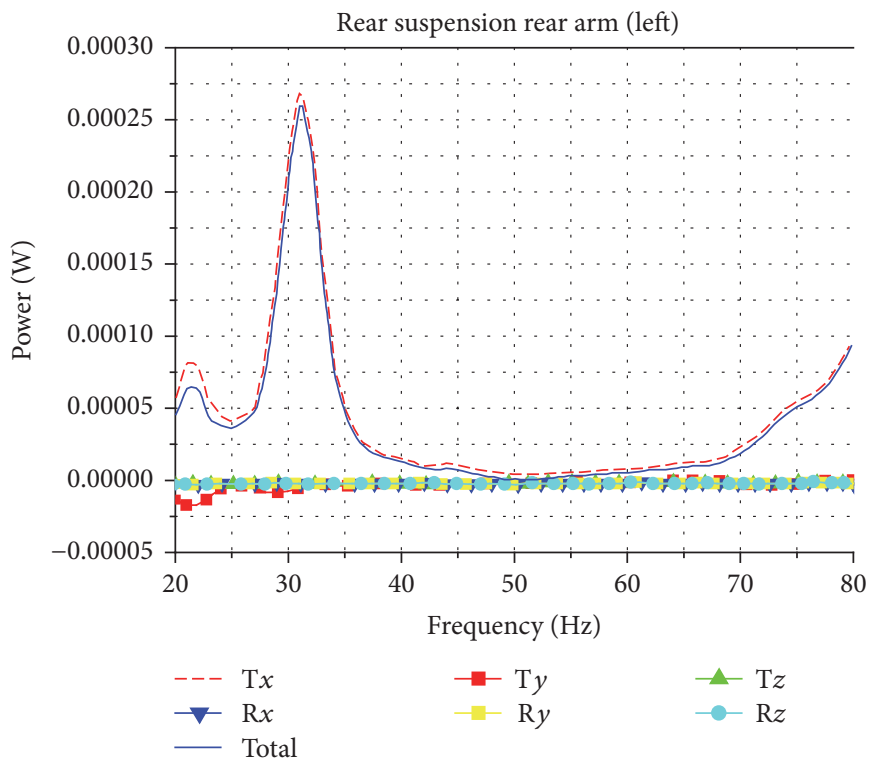

(b) Left

Figure 15: Power of rear suspension lower arm in 6 directions.

TABle 3: Analysis time of finite element model.

\begin{tabular}{lcccc}
\hline Computation method & Analysis project & DOFs/million & Time consumed/hours & Total time consumed/hours \\
\hline Conventional FEM & Frequency response of full vehicle & 9.5 & 5 & 5 \\
\hline \multirow{2}{*}{ Substructure FEM } & Chassis FRF analysis & 3.5 & 1 & 4.07 \\
& Body FRF analysis & 6 & 3 & 0.07 \\
\hline
\end{tabular}




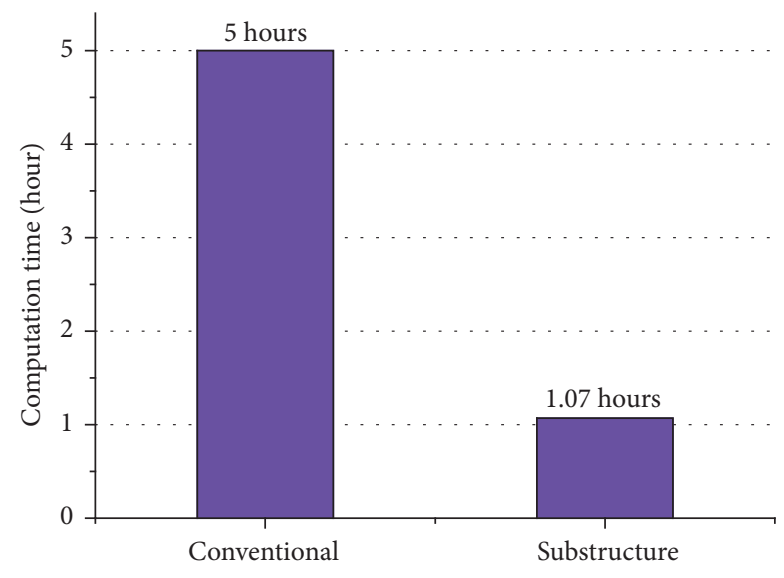

FIgURE 16: Optimization of chassis.

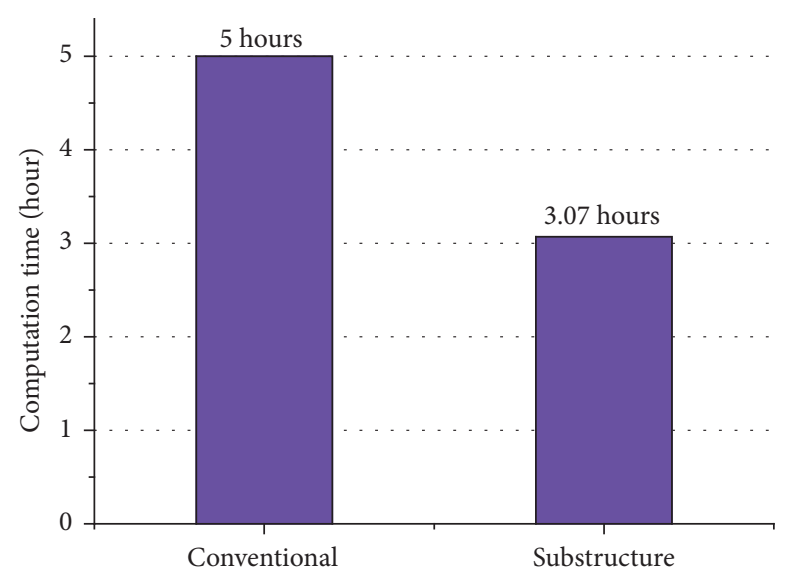

FIGURE 17: Optimization of body.

FRF matrix file of the body, with the application of substructure method, only the FRF of optimized chassis substructure needs to be recomputed. And then the FRF matrixes of each substructure are combined and frequency response analysis is carried out, taking about 1.07 hours in total. Compared with the conventional FEM, this method reduces the analysis time from 5 hours to 1.07 hours, and the efficiency is improved by $78 \%$, as shown in Figure 16.

(2) The body substructure needs to be optimized. With the application of substructure method, only the FRF of the optimized body substructure needs to be recomputed. Subsequently, the FRF matrixes of each substructure are combined and frequency response analysis is carried out, which takes about 3.07 hours in total. Compared with the conventional FEM, which can be found in Figure 17, this method reduces the analysis time from 5 hours to 3.07 hours, and the efficiency is accordingly improved by $38 \%$.

(3) In order to optimize the parameter of vibration isolators between chassis and body substructure, only

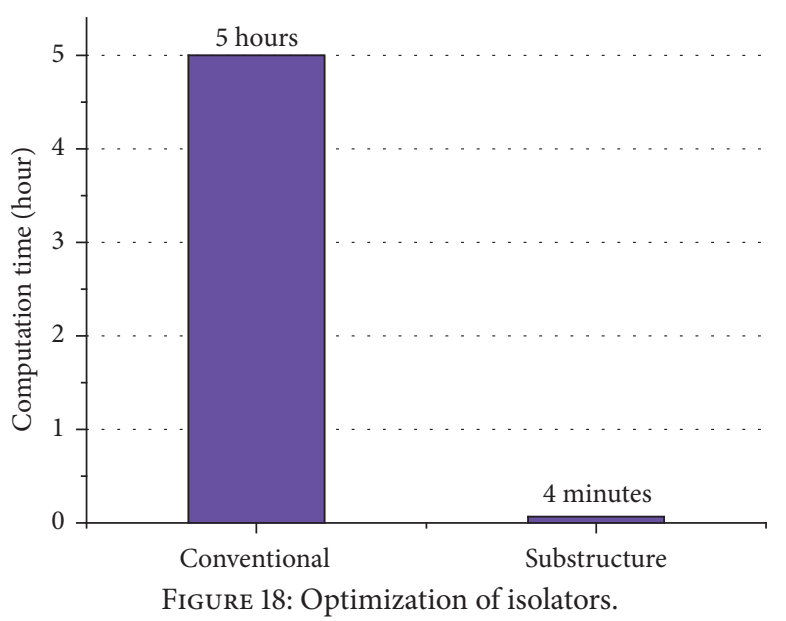

TABLE 4: Analysis time of optimization.

\begin{tabular}{lccc}
\hline & $\begin{array}{c}\text { Conventional } \\
\text { FEM/hours }\end{array}$ & $\begin{array}{c}\text { Substructure } \\
\text { FEM/hours }\end{array}$ & $\begin{array}{c}\text { Efficiency } \\
\text { improved }\end{array}$ \\
\hline $\begin{array}{l}\text { Chassis } \\
\text { optimization }\end{array}$ & 5 & 1.07 & $78 \%$ \\
$\begin{array}{l}\text { Body } \\
\text { optimization }\end{array}$ & 5 & 3.07 & $38 \%$ \\
$\begin{array}{l}\text { Isolators } \\
\text { optimization }\end{array}$ & 5 & 0.07 & $98 \%$ \\
\hline
\end{tabular}

the DAMP code needs to be rewritten, which takes just about 0.07 hours in total. In comparison with the 5 hours required by the conventional method, this optimization scheme takes only 4 minutes, and the analysis efficiency is improved by $98 \%$, as presented in Figure 18.

Briefly, the application of substructure FEM analysis of frequency response greatly shortens the engineering computation time. As for chassis structure optimization scheme, the efficiency is improved by $78 \%$; when it comes to body optimization scheme, the efficiency is improved by $38 \%$; regarding vibration isolators' optimization scheme, the efficiency is improved by $98 \%$. Details are displayed in Table 4 . In the optimization analysis with many schemes, the superiority of substructure method is palpably reflected.

\section{Experimental Verification}

6.1. Optimization of Transmission Shaft Support Bushing. The transmission shaft support bushing is made of soft rubber, and its function is to reduce the unbalanced vibration of the transmission shaft transferring to the body structure $[17,18]$. Its location is the point 20 in Figure 10. Figure 19(a) exhibits the installation of transmission shaft support bushing; Figure 19(b) shows the original sample of the studied vehicle, whose stiffness is $50 \mathrm{HA}$; Figure 19(c) shows the optimized 1\# sample, whose stiffness is $40 \mathrm{HA}$ and Figure 19(d) presents 


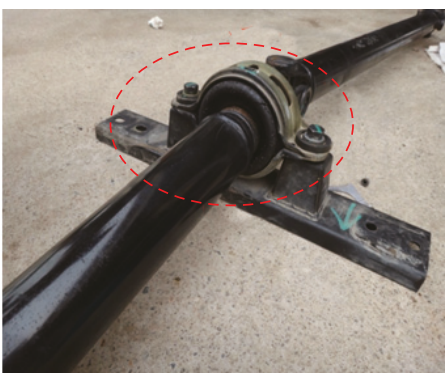

(a) Installation

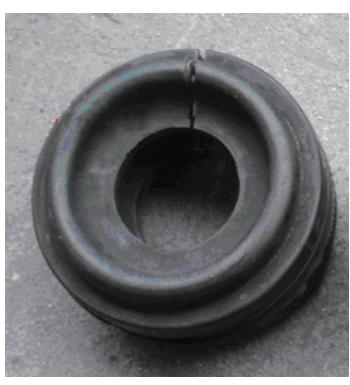

(b) Original sample $50 \mathrm{HA}$

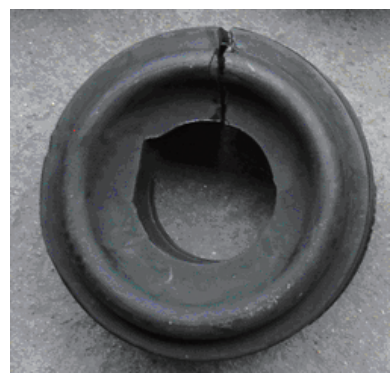

(c) 1\# sample $40 \mathrm{HA}$

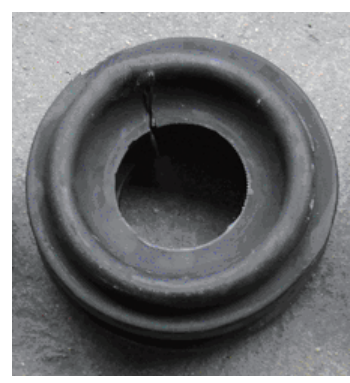

(d) 2\# sample $70 \mathrm{HA}$

FIGURE 19: Samples of transmission shaft support bushing.

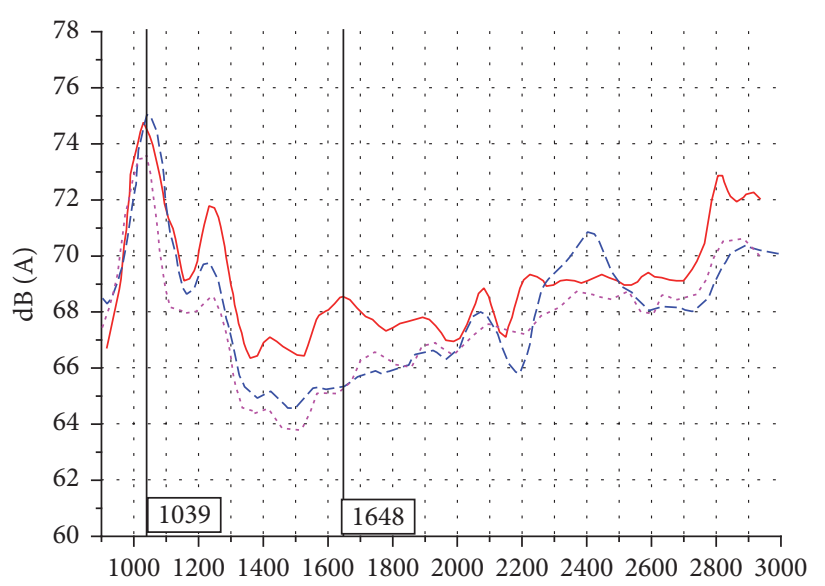

(rmp)

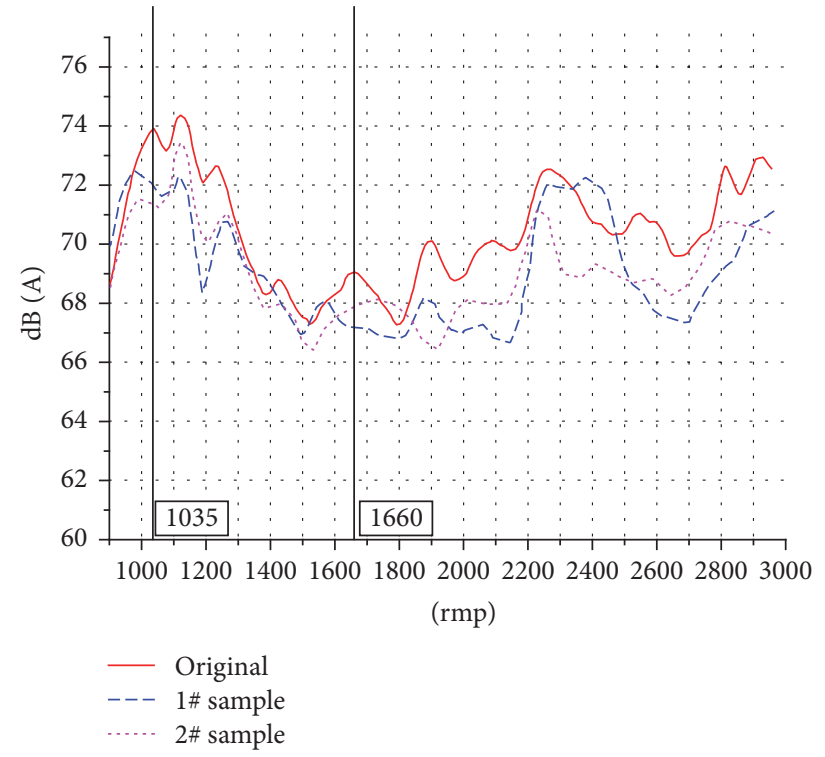

(b) Middle of second seats

(a) Driver's right ear

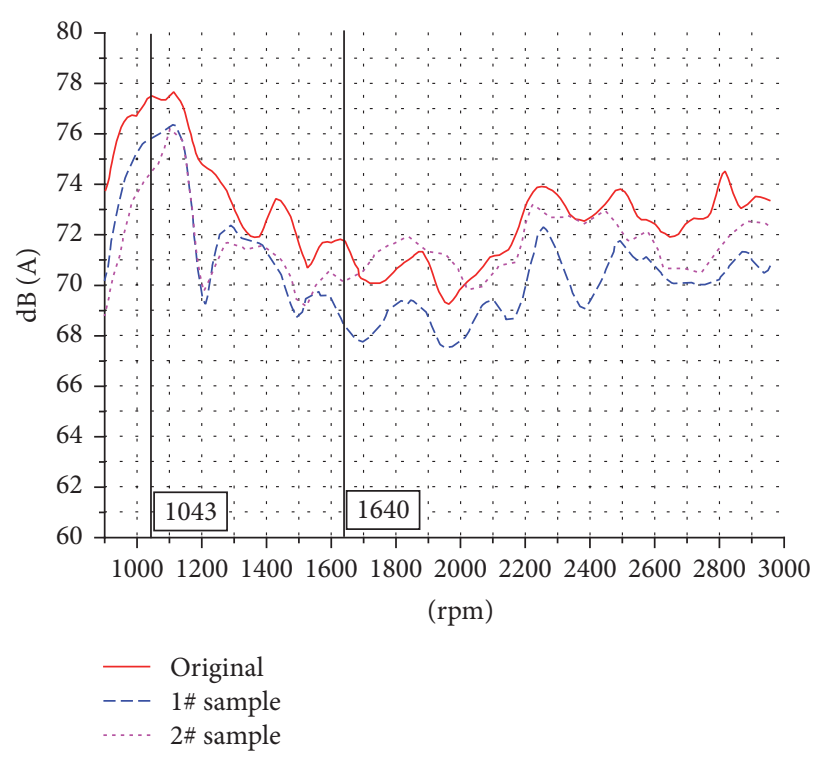

(c) Middle of rear seats

Figure 20: Interior noise response. 


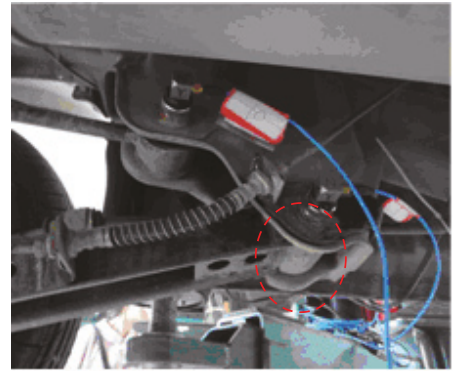

(a) Installation

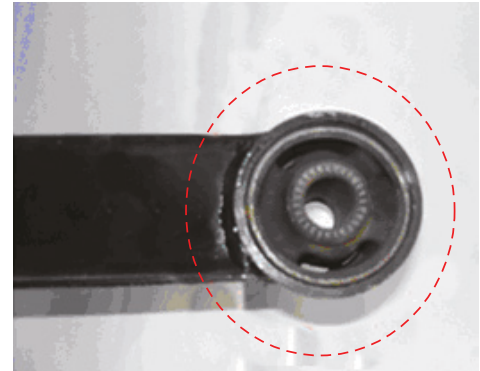

(b) Original Sample

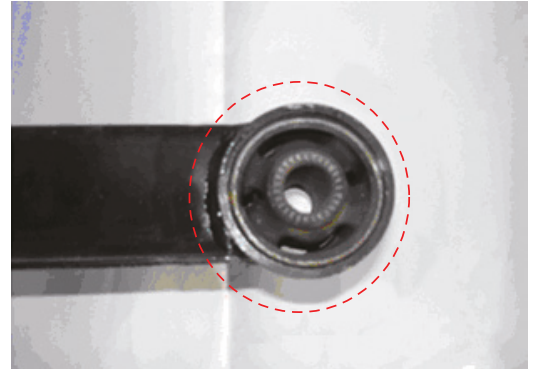

(c) 3\# sample

FIGURE 21: Samples of rear suspension lower arm bushing.

the optimized 2\# sample, whose stiffness is $70 \mathrm{HA}$. There is positive correlation between the hardness and stiffness of rubber. The $1 \#$ sample and 2 \# sample are separately installed, and experiment verification is carried out.

Figure 20 shows the interior noise response when the vehicle rapidly speeds up in the 4 th gear. Compared with the test data of the original sample, 1\# sample has exerted little effect on noise around $1050 \mathrm{rpm}$, but there is a reduction of about $2 \mathrm{~dB}$ at around $1650 \mathrm{rpm}$. According to 2\# sample, the noise response is palpably improved at around $1050 \mathrm{rpm}$ and $1650 \mathrm{rpm}$. The noise at the middle seats and rear seats is reduced by $3 \mathrm{~dB}$, and the noise at the location of driver's right ear is reduced by $3 \mathrm{~dB}$. The $2 \#$ sample whose stiffness is $70 \mathrm{HA}$ enhances the radial stiffness and effectively isolates the unbalanced rotation. With the decline of transmission energy at this point, the interior noise around $1050 \mathrm{rpm}$ and $1650 \mathrm{rpm}$ is palpably reduced.

\subsection{Optimization of Rear Suspension Lower Arm Bushing.} The bushing of rear suspension lower arm is made of rubber, whose main function is to attenuate the vibration transferred from suspension. The installation locations are points 8 and 9 in Figure 10. Figure 21(a) shows the installation. Figure 21(b) is the original bushing sample, and Figure 21(c) presents the optimized 3\# sample. Two through-holes with diameter of $10 \mathrm{~mm}$ are added to reduce radical stiffness.

The interior noise is tested when the vehicle rapidly speeds up at the 4th gear, and related data can be found in Figure 22. Compared with the original noise testing curve, 3\# sample improves the noise performance at around $1050 \mathrm{rpm}$. The noise is, respectively, reduced at the location of driver's right ear, middle of second seats, and middle of rear seats by $5 \mathrm{~dB}, 3 \mathrm{~dB}$, and $2 \mathrm{~dB}$. In, $3 \#$ sample two through-holes with $10 \mathrm{~mm}$ diameter are added, reducing radical stiffness. This scheme efficiently attenuates the vibration from suspension and palpably improves the noise performance at around $1050 \mathrm{rpm}$.

\section{Conclusion}

To conclude, this paper combined the substructure modeling and power flow theory and derived the function of vibration transmission force and vibration velocity at each interface. The finite element model based on substructure was developed and was used in the analysis of substructure power flow characteristics.

(1) Simple vehicle model was selected as an example, and vibration and acoustic characters were analyzed based on MSC.NASTRAN. The accuracy of substructure frequency response analysis method was verified by comparing with the conventional FEM solution.

(2) Combined with the NVH finite element model of full vehicle and substructure frequency response analysis method, the present study investigated the risky paths causing interior noise and the vibration modes in these paths from the perspective of energy. And then the stiffness of transmission shaft support bushing increased and the radial stiffness of rear suspension lower arm bushing decreased. Through conducting the experimental test, the interior noise was palpably improved.

(3) The substructure frequency response analysis method retains the FRF matrix of each substructure, so the unchanged substructure does not need to be recomputed in the subsequent optimization analysis. This will significantly shorten the engineering computation, and the analysis efficiency will be improved. When it comes to the optimization schemes of chassis, body, and vibration isolators, the computation efficiency can be raised by $78 \%, 38 \%$, and $98 \%$, respectively. 


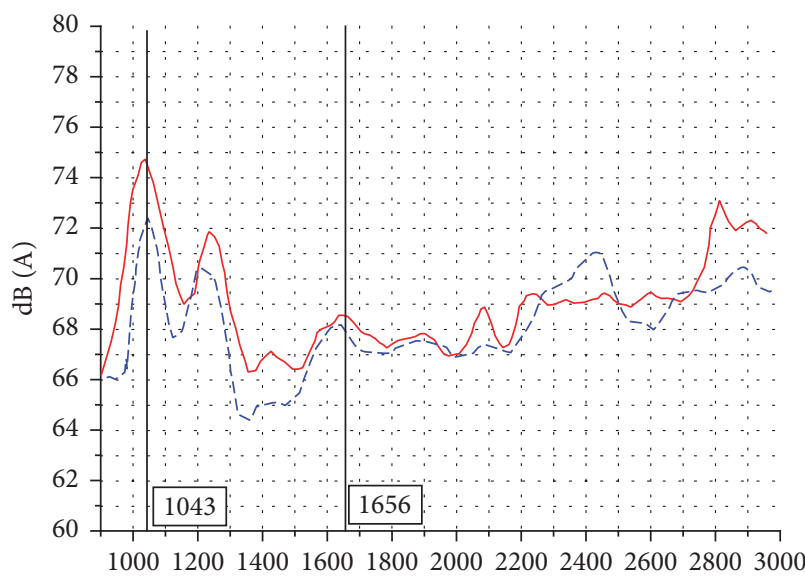

(rpm)

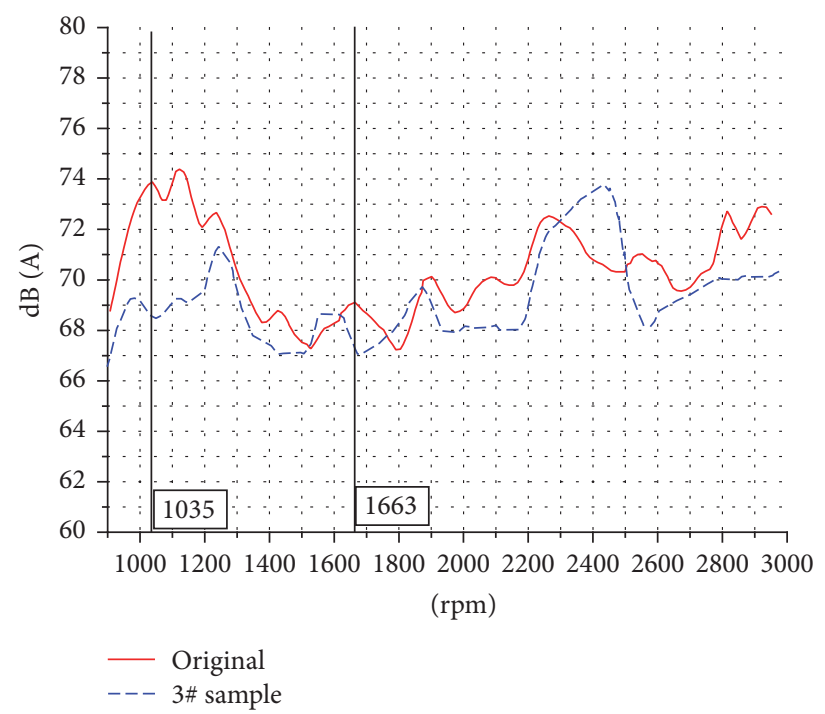

(b) Middle of second seats

(a) Driver's right ear

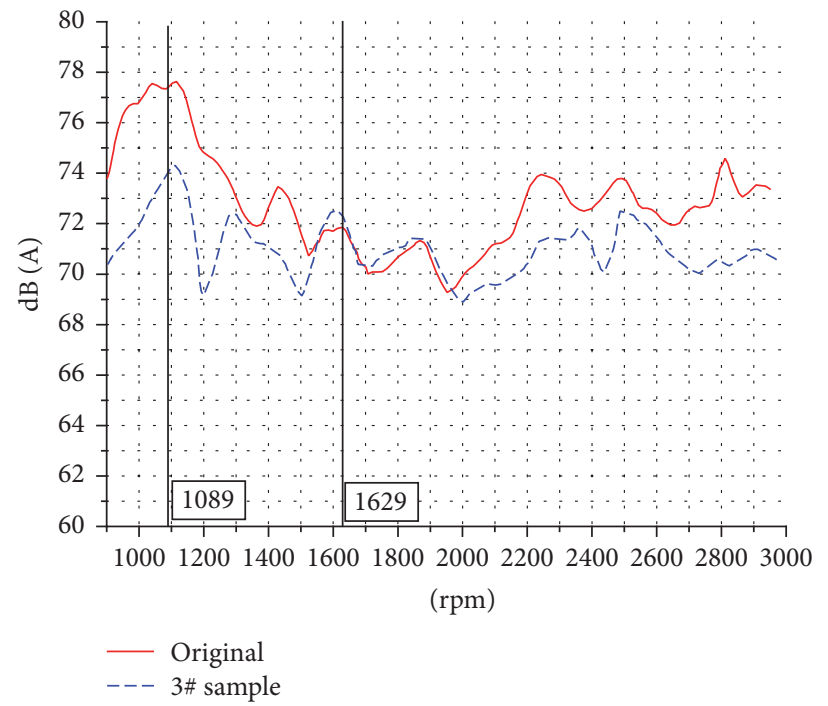

(c) Middle of rear seats

FIGURE 22: Interior noise response.

\section{Conflicts of Interest}

The authors declare that there are no conflicts of interest regarding the publication of this paper.

\section{Acknowledgments}

This project is supported by National Natural Science Foundation of China (Grant no. 51575410).

\section{References}

[1] N. Hampl, "Advanced simulation techniques in vehicle noise and vibration refinement," in Vehicle Noise \& Vibration Refinement, chapter 8, pp. 174-188, 2010.
[2] D. J. Nefske and S. H. Sung, "Power flow finite element analysis of dynamic systems: basic theory and application to beams," Journal of Vibration, Acoustics, Stress, and Reliability in Design, vol. 111, no. 1, pp. 94-100, 1989.

[3] H. G. D. Goyder and R. G. White, "Vibrational power flow from machines into built-up structures, part I: introduction and approximate analyses of beam and plate-like foundations," Journal of Sound and Vibration, vol. 68, no. 1, pp. 59-75, 1980.

[4] Y. P. Xiong, J. T. Xing, and W. G. Price, "Power flow analysis of complex coupled systems by progressive approaches," Journal of Sound \& Vibration, vol. 239, no. 2, pp. 275-295, 2001.

[5] G. Zhang, M. Castanier, C. Pierre, and Z. Mourelatos, "Vibration and power flow analysis of a vehicle structure using characteristic constraint modes," SAE Technical Paper 2003-011602, SAE International, 2003. 
[6] S. K. Lee, "Application of vibrational power flow to a passenger car for reduction of interior noise," Shock and Vibration, vol. 7, no. 5, pp. 277-285, 2000.

[7] C. Q. Liu and X. Liu, "A new method for analysis of complex structures based on FRF's of substructures," Shock \& Vibration, vol. 11, no. 1, pp. 1-7, 2004.

[8] C. Q. Liu, "Combination of an improved FRF-based substructure synthesis and power flow method with application to vehicle axle noise analysis," Shock and Vibration, vol. 15, no. 1, pp. 51-60, 2008.

[9] S. A. Hambric, S. H. S. Consultant, and D. J. N. Consultant, Hybrid Transfer Path Analysis, chapter 13, John Wiley \& Sons, Ltd, New York, NY, USA, 2016.

[10] Z. Yanyan and G. Feng, "Modal stimulation analysis for acoustic-structure coupling system of the aluminum alloy metro vehicle cavity," in Proceedings of the International Conference on Electric Information and Control Engineering (ICEICE '11), pp. 5951-5956, April 2011.

[11] C. J. Cameron, P. Wennhage, and P. Göransson, "Prediction of $\mathrm{NVH}$ behaviour of trimmed body components in the frequency range 100-500 Hz," Applied Acoustics, vol. 71, no. 8, pp. 708-721, 2010 .

[12] B. Sakhaei and M. Durali, "Vibration transfer path analysis and path ranking for NVH optimization of a vehicle interior," Shock \& Vibration, vol. 2014, Article ID 697450, 5 pages, 2014.

[13] M. Palmonella, M. I. Friswell, J. E. Mottershead, and A. W. Lees, "Guidelines for the implementation of the CWELD and ACM2 spot weld models in structural dynamics," Finite Elements in Analysis \& Design, vol. 41, no. 2, pp. 193-210, 2004.

[14] T. Ahlersmeyer, "Advanced experimental techniques in vehicle noise and vibration refinement," in Vehicle Noise \& Vibration Refinement, chapter 9, pp. 189-216, 2010.

[15] C. G. Liu, Research on Car Interior Noise Control and Structure Optimization, Hunan University, 2011.

[16] J. K. Bennighof, M. F. Kaplan, M. Kim, C. W. Kim, and M. B. Muller, "Implementing automated multi-level substructuring in NASTRAN vibroacoustic analysis," in Proceedings of the SAE Noise \& Vibration Conference \& Exposition, 2001.

[17] M. Coja and L. Kari, "Axial audio-frequency stiffness of a bush mounting-the waveguide solution," Applied Mathematical Modelling, vol. 31, no. 1, pp. 38-53, 2007.

[18] E. Lindberg, M. Östberg, N.-E. Hörlin, and P. Göransson, "A vibro-acoustic reduced order model using undeformed coupling interface substructuring - application to rubber bushing isolation in vehicle suspension systems," Applied Acoustics, vol. 78, pp. 43-50, 2014. 


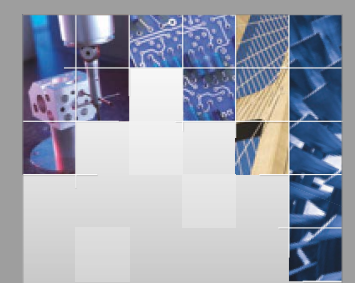

\section{Enfincering}
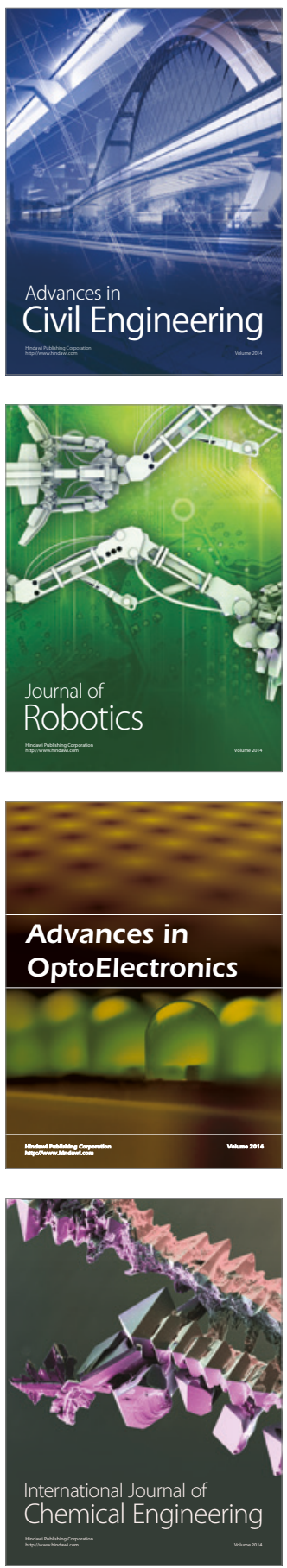

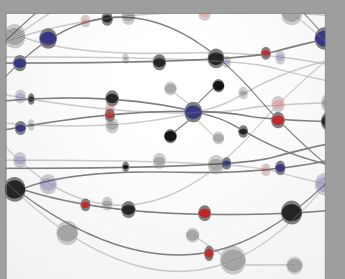

The Scientific World Journal

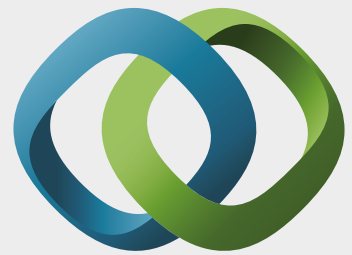

\section{Hindawi}

Submit your manuscripts at

https://www.hindawi.com
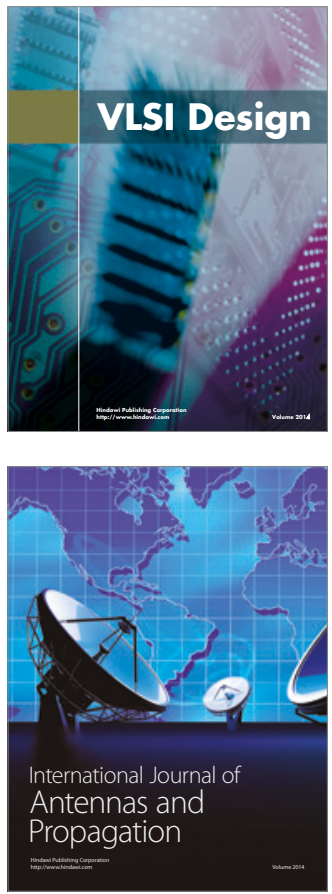

\section{Rotating}

Machinery
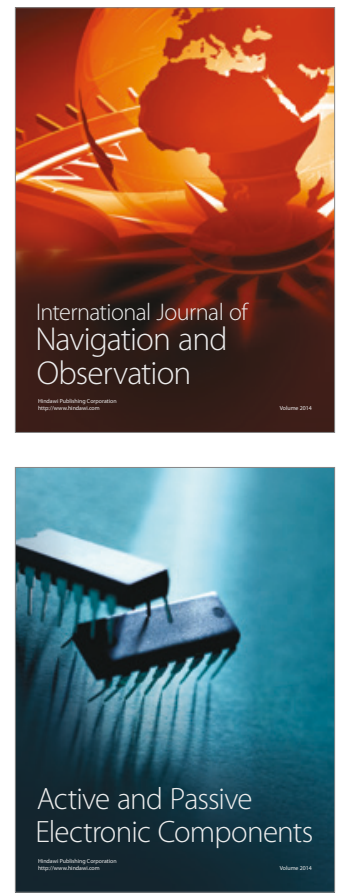
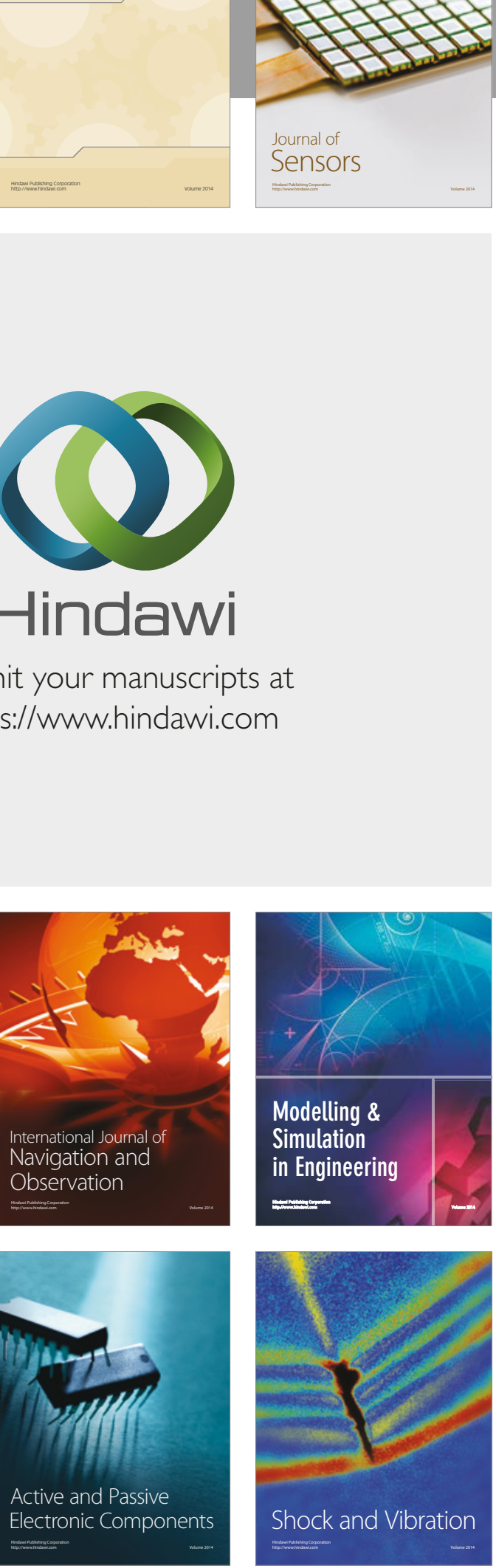
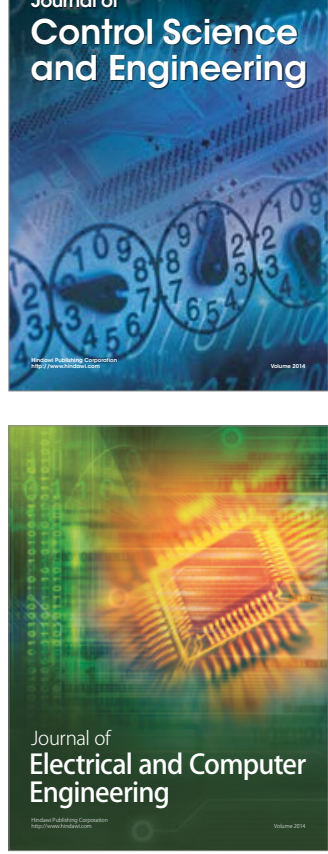

Distributed

Journal of

Control Science

and Engineering
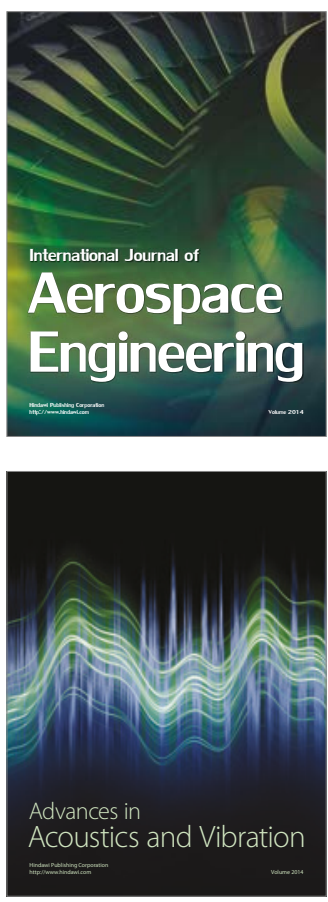

Sensor Networks 